\title{
Review \\ Systematic Literature Review of System Models for Technical System Development
}

\author{
Marvin M. Schmidt ${ }^{1, *, \dagger}$, Thomas C. Zimmermann ${ }^{1, \dagger}$ and Rainer Stark ${ }^{1,2}$ \\ 1 Fraunhofer Institute for Production Systems and Design Technology IPK, 10587 Berlin, Germany; \\ Thomas.Zimmermann@ipk.fraunhofer.de (T.C.Z.); rainer.stark@tu-berlin.de (R.S.) \\ 2 Department of Industrial Information Technology, Institute for Machine Tools and Factory Management, \\ Technische University, 10587 Berlin, Germany \\ * Correspondence: Marvin.Michael.Schmidt@ipk.fraunhofer.de; Tel.: +49-30-39006-478 \\ + These authors contributed equally to this work.
}

check for updates

Citation: Schmidt, M.M.;

Zimmermann, T.C.; Stark, R.

Systematic Literature Review of System Models for Technical System Development. Appl. Sci. 2021, 11, 3014. https://doi.org/10.3390/ app11073014

Academic Editor: Dov Dori

Received: 26 January 2021

Accepted: 23 March 2021

Published: 28 March 2021

Publisher's Note: MDPI stays neutral with regard to jurisdictional claims in published maps and institutional affiliations.

Copyright: (c) 2021 by the authors. Licensee MDPI, Basel, Switzerland. This article is an open access article distributed under the terms and conditions of the Creative Commons Attribution (CC BY) license (https:// creativecommons.org/licenses/by/ $4.0 /)$.

\begin{abstract}
In Model-Based Systems Engineering (MBSE) there is yet no converged terminology. The term 'system model' is used in different contexts in literature. In this study we elaborated the definitions and usages of the term 'system model', to find a common definition. We analyzed 104 publications in depth for their usage and definition as well as their meta-data e.g., the publication year and publication background to find some common patterns. While the term is gaining more interest in recent years, it is used in a broad range of contexts for both analytical and synthetic use cases. Based on this, three categories of system models have been defined and integrated into a more precise definition.
\end{abstract}

Keywords: model-based systems engineering (MBSE); model informatics and analytics; model-based collaboration

\section{Introduction}

While the research and industrial interest in Model-Based Systems Engineering (MBSE) is very high - as this special issue of Multidisciplinary Digital Publishing Institute (MDPI) shows-there is yet no common terminology for this topic. Huldt and Stenius [1] mentioned that 'the definition of MBSE is not yet internationally converged and standardized. As a consequence, the definition of MBSE is rather vague and open to a broad range of interpretations of the concept'. Even though the model of a system is seen as the main artifact in MBSE [2], there is also yet no common definition for the term 'system model', which the model is often referred to. In 2015, Hart [3] mentioned, that a system model is '[...] a structured representation that focuses on the overall system requirements, behavior, structure, properties and interconnections'. This definition is as vague as the MBSE definition mentioned by Huldt and Stenius [1]. Despite the vagueness of the existing definitions, the concept of systems modeling increases in popularity across various industries. This also means multiple definitions and concepts, which are difficult to compare. From an industry perspective, this means information and results are difficult to exchange between different systems modeling eco-systems both internally and externally. The widespread, but fragmented understanding poses a challenge for research and academia, since there is no universal understanding or grand theory of systems modeling which could function as a base from which to extend on existing knowledge. Therefore, on one hand, it is important to understand how different organizations in different industries apply the concepts they define as systems modeling to meet their individual needs in order to then identify recurring schemes and similarities. On the other hand, inconsistencies and contradictions help to identify gaps and areas of improvement to derive future solutions that are needed to advance systems development through the use of system models. 
In order to evaluate those points in particular, as well as the current state of system model application and development for engineering systems across various industries in general, the following research questions have been addressed in this study:

1. How is the term 'system model' used in MBSE and further domains?

2. Who uses 'system models' besides Systems Engineers?

3. Is it possible to have more than one 'system model' per system?

The following hypotheses are connected to these research questions:

1. There is yet no converged overall definition of the term 'system model'.

2. A 'system model' can be created in different ways and is not limited to the application of Systems Modeling Language (SysML).

3. The usage of a 'system model' is not limited to the domain of System Engineers.

This paper is structured as follows. In Section 2, the method used for the systematic literature review is introduced. This includes, for example, the search strategy, the eligibility criteria and information sources. The results of this systematic literature review are listed in Section 3. Screened studies are presented and discussed in the context of biases. Eventually, the findings of the synthesis of these studies are discussed in Section 4. This includes limitations, e.g., based on the bias, as well as an overall conclusion regarding the hypotheses listed above.

\section{Materials and Methods}

The systematic literature review has been carried out without a systemic review protocol.

The study focused on international definition and thus on titles in English. Due to the native language of the authors being German, literature written in German has been declared as eligible as well with the term 'Systemmodell' being equivalent to the English term 'system model'. To get a full overview of any possible definition of the term 'system model' the year of publication has not been limited in any form. The eligibility has mainly been based on the reference to engineered systems and a possible correlation to MBSE.

The scanning period is dated from 18 July 2020 to 31 July 2020. Information sources included the databases Scopus by Elsevier (www.scopus.com (accessed on 21 July 2021)), Web of Science by Clarivate (apps.webofknowledge.com (accessed on 28 July 2021)), SAGE Journals by SAGE Publications (journals.sagepub.com (accessed on 22 July 2021)), IEEExplore of the Institute of Electrical and Electronics Engineers (IEEE) (ieeexplore.ieee.org (accessed on 24 July 2021)) and arXiv.org made available by the Cornell University (arxiv.org (accessed on 31 July 2021)). As of 18 November, Scoupus includes 41462 journals, proceedings, books and trade publications (https: / / www.scopus.com/sources.uri (accessed on 18 November 2021)) from 1960-2020. Web of Science covers 21,419 books, proceedings and journals from 1900-2020 (https:/ / clarivate.libguides.com/webofscienceplatform/coverage (accessed on 18 November 2021)). IEEExplore includes 5,329,188 articles from journals, conferences, early access publications, standards, magazines, courses and books. The date coverage goes from 1872-2021. Sage Journals dates back from 1847-2021 and accesses 1211 journals. arXiv.org covers 1795706 open-access articles explicitly submitted to arXiv.org with a date coverage of 1991-2020.

Table 1 summarizes this information and gives an overview of the content of the database.

Table 1. Overview of information sources.

\begin{tabular}{|c|c|c|c|}
\hline Source Name & Date Coverage & Last Searched & Comments on Included Data \\
\hline Scopus & 1960-2020 & 21 July 2020 & 41,462 journals, proceedings, trade publications and books \\
\hline Web of Science & 1970-2020 & 28 July 2020 & 21,419 books, proceedings and journals \\
\hline Sage Journals & $1847-2020$ & 22 July 2020 & 1211 journals \\
\hline IEEExplore & $1872-2021$ & 24 July 2020 & $\begin{array}{l}5,329,188 \text { articles from journals, conferenes, early access publica- } \\
\text { tions, standards, magazines, courses and books }\end{array}$ \\
\hline arXiv.org & $1991-2020$ & 31 July 2020 & $\begin{array}{l}\text { 1,795,706 open-access articles (only explicitly submitted to arXiv. } \\
\text { org) }\end{array}$ \\
\hline
\end{tabular}


No additional sources have been used.

As the search for the term 'system model' would bring too many results regarding different kinds of non-technical systems and models in various contents, the keywords have been refined. The following keywords have been used:

1. federated system model

2. system model creation

3. system model development

4. system model usage

5. system model fidelity

6. system model complexity

7. system model uncertainty

8. multi-model networks

9. model hierarchy

10. system model perspectives

11. system model visualization

12. system model characteristics

13. transdisciplinary system model

14. interdisciplinary system model

15. system model + MBSE

16. system of systems model

The search for these keyword-searches has been carried out as demonstrated in the following for the Scopus database:

1. The advanced search of the database has been located and the keywords were entered for searching the title, abstract and keywords, if available. The keyword combination has been combined with logical 'AND' to limit the results. Range of year, language and authors have not been limited. If the keyword combination raised too many results, i.e., exceeded 1000 results, the keywords have been combined with quotation marks. An exemplary search string for Scopus is TITLE-ABS-KEY ("system model" AND development). All keyword combinations are attached in the Appendix A as Tables A1-A5.

2. All titles have been exported as *..csv (or if a *.csv has not been available as *.bib) files. If the total number of entries exceeded the limit for export, it has been split into partial exports and was combined locally. For arXiv.org a script for the Application Programming Interface (API) has been written to export the information into a *.Csv file, which is shown in Appendix B.

3. The *.csv files containing all results for a search string have been combined to an overall data table. To allow easier filtering, the *.csv-files have been imported into Microsoft Excel and analyzed as *.xlsx file.

The following methodology was based on the Preferred Reporting Items for Systematic Reviews and Meta-Analyses (PRISMA) workflow [4]. It is depicted in the following Figure 1.

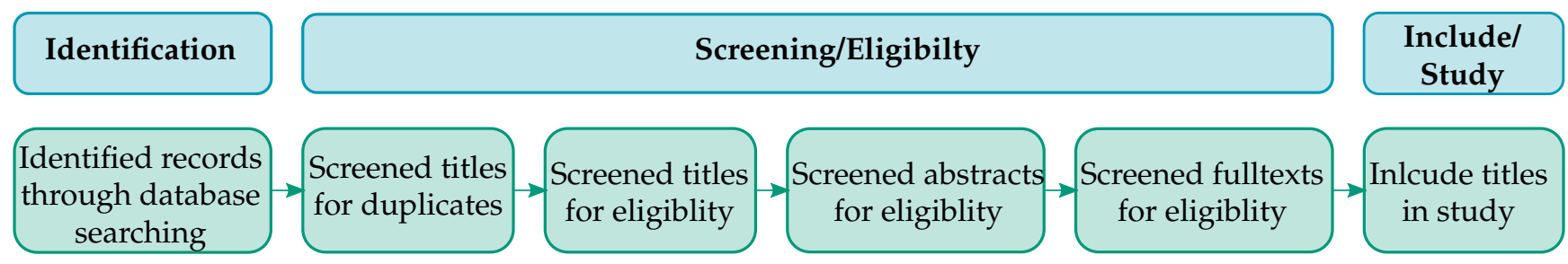

Figure 1. Workflow for selecting studies for the systematic literature review based on the PRISMA workflow [4].

The table produced in the final step of the identification process with the keyword search has been screened for duplicates. This included identical titles, titles with different capitalization of the words and abbreviated titles with identical listed authors and year. 
The rest of the titles has been screened for eligibility. As the defined criteria did not exclude any year or, this step mainly focused on selecting titles in English or German and excluding most non-engineered systems. In the following, the same procedure has been applied to the selected publications abstracts and associated full-texts in the final screening step. The screening for eligibility has been performed by two reviewers. Ambiguities and disagreements between them were resolved by consensus. The number of publications that remained have been included in the study.

The data has been manually extracted by copying and summarizing the relevant information of each publication into comments in the PDF and transferring these comments into a tabulated data-set. The extracted items have been discussed by the two review authors and whenever a disagreement was reached, a third reviewer was contacted. This study focused on the definition and usage in literature, none of the authors have been contacted for further details, as this might lead to biases in the analysis.

As this literature review here does not focus on quantitative values that have been analyzed in other studies the process of extraction of data was about identifying the meaning for the topics of interest. These topics focused on three variables:

1. Domain/origin/background of the systems under consideration,

2. Definition or meaning of the term 'system model' and

3. Usage of the 'system model'.

While the different domains represented in the publications could raise some bias in another context it was used here as the first variable under consideration. Further risk of bias has been assessed by two authors collecting the data of the studies independently. Principle measures have been the quantities of specific origins, definitions, creation approaches and usage description for 'system models' (defined variables listed above). The analysis of the studies was performed by clustering the data-set with respect to the definition of the term 'system model'. These clusters have been investigated for specific domains for the system under consideration as well as their stated creation and usage methods. Additionally, the authors and years of publication have been analyzed to asses the risk of bias across studies.

\section{Results}

In this section, the literature body as a result of the PRISMA workflow from Figure 1 is first described and then the analysis of its content is presented.

\subsection{Selected Studies for Literature Body}

The following Figure 2 shows the number of results which pertained each step of the methodological approach of Figure 1.

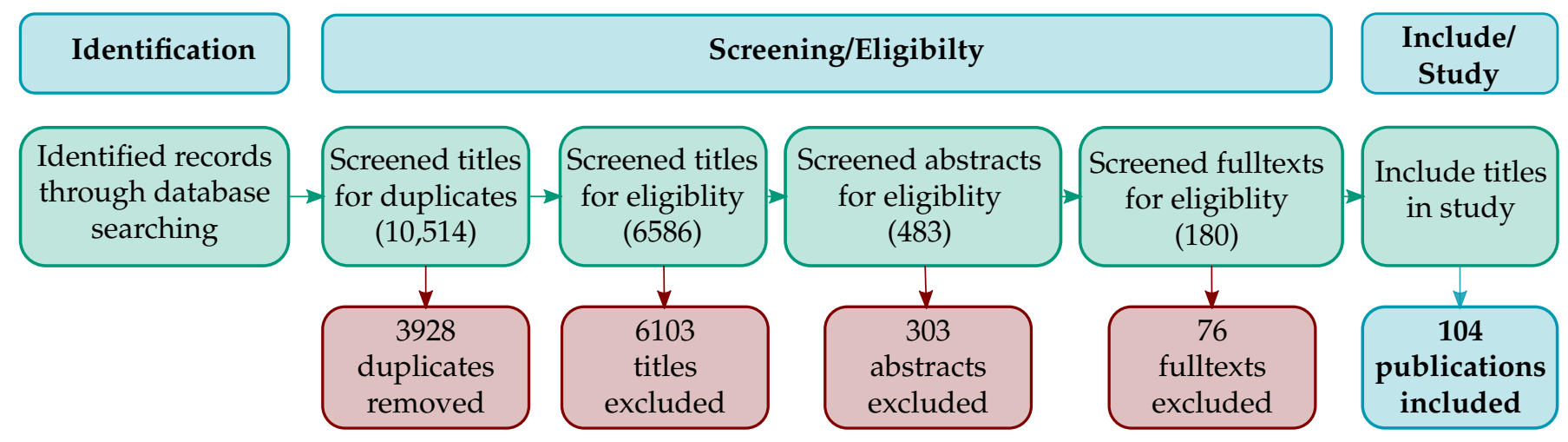

Figure 2. Results of literature screening.

As result of the database search described in Section 2 10,514 records have been extracted. After screening for duplicates, the 6586 left titles have been screened for eligibility 
depending on the eligibility criteria (engineered systems as target systems and a possible correlation to MBSE) mentioned in Section 2. With this procedure, 6103 titles have been excluded as they were not fitting within the topic of interest. This was primarily achieved by investigating the titles for fitting into the topic of model-based technical system development. The rest of 483 publications have been investigated in their abstracts and after excluding 303 mainly due to different scopes (e.g., full software systems in scope or no existing full-texts to be found for the publication) the rest of the 180 publications was read in more detail with the same criteria. While reading the publications in more detail, it turned out, that 76 of them were still out of scope and thus, 104 publications have been included in this study and are listed in the following Table 2. This table lists the publications in chronological order (focusing on the year and not the month of publication) with their reference, year of publication, type of publication, the domain of the target system under consideration in the publication, the category of work behind the publication, whether the system model is a single model or consists of multiple models and whether the model is used for analytics or synthesis of the target system. The different columns of the table will be investigated in the following subsections.

\subsection{Description of the Literature Body}

In the following subsections the literature body will be described and characterized in terms of scientific sources, types of use cases and industry context in order to classify and subsequently discuss the results. It shall be mentioned that all mentions of 'raw search results' focus on the results after the duplicate removal.

Figure 3 displays the distribution over publication types.

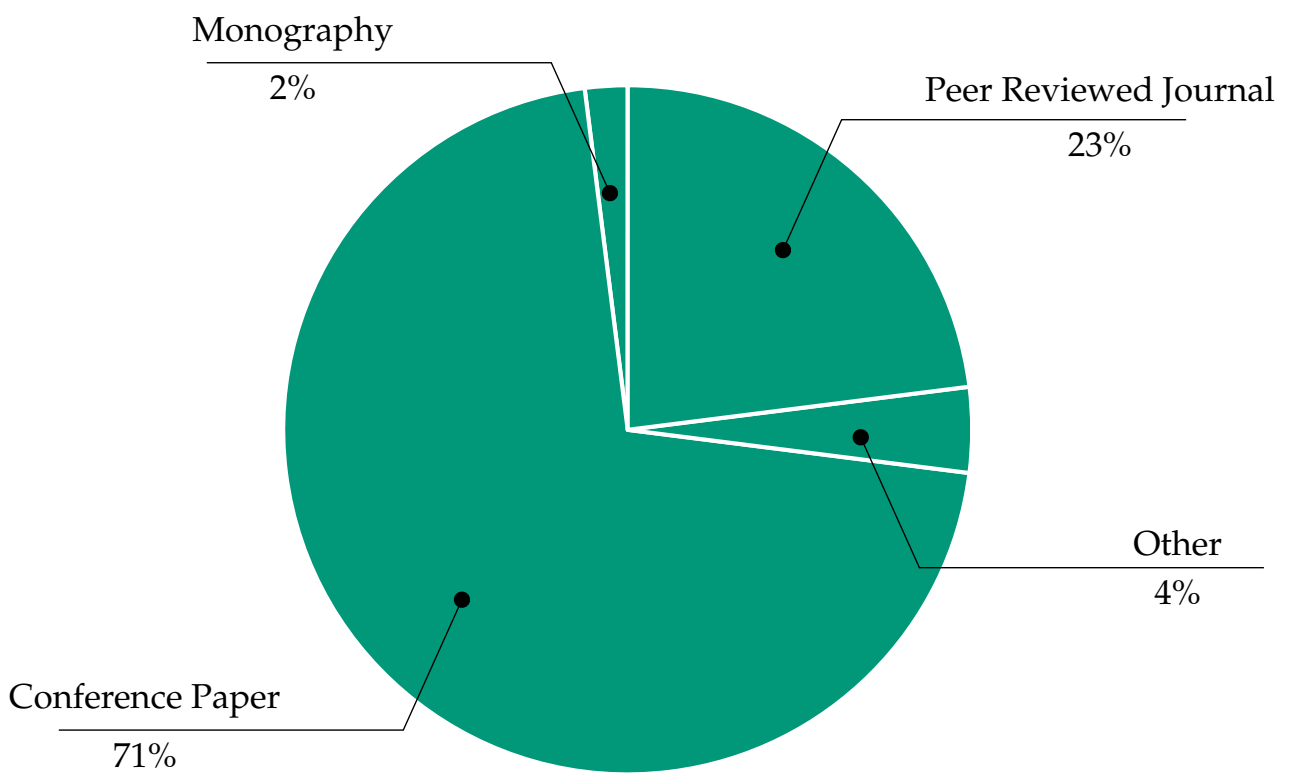

Figure 3. Percentage of each publication in literature body.

The body of literature consists primarily of conference papers and articles published in peer-review journals not associated with a conference. Combined, those make up $94 \%$ percent of the selected samples, with monographs only accounting for $2 \%$ of the literature body. 'Other' in Figure 3 represents articles published without going through a peer-review process. 
Table 2. Literature overview of eligible publications.

\begin{tabular}{|c|c|c|c|c|c|c|}
\hline Reference & Year & Type & Domain & Category & Multitude & Usage \\
\hline Capehart [5] & 1977 & Journal Article & Production Systems & theoretical concept & single & analytics \\
\hline Joshi et al. [6] & 1995 & Journal Article & Production Systems & theoretical concept & multiple & synthesis \\
\hline Ironmonger et al. [7] & 1996 & Conference Paper & Energy & prototype & single & analytics \\
\hline Bluff [9] & 1999 & Journal Article & Air and land vehicle & theoretical concept & multiple & synthesis \\
\hline Estanbouli et al. [10] & 2004 & Conference Paper & Other & theoretical concept & single & analytics \\
\hline Hicks et al. [11] & 2004 & Journal Article & Other & theoretical concept & single & synthesis \\
\hline Wilson et al. [12] & 2007 & Journal Article & Defense & theoretical concept & single & analytics \\
\hline Ma et al. [14] & 2008 & Conference Paper & Energy & theoretical concept & single & analytics \\
\hline Curry et al. [15] & 2008 & Journal Article & Other & theoretical concept & single & analytics \\
\hline Sturm [16] & 2008 & Conference Paper & Defense & theoretical concept & single & synthesis \\
\hline Wakefield and Miller [17] & 2008 & Conference Paper & Air and land vehicle & theoretical concept & multiple & analytics \\
\hline Amrhein et al. [18] & 2008 & Journal Article & Air and land vehicle & theoretical concept & both & analytics \\
\hline Hoang et al. [19] & 2008 & Conference Paper & Space Technology & $\ldots$ & multiple & analytics \\
\hline Hummel and Braun [20] & 2008 & Conference Paper & not specified & theoretical concept & multiple & analytics \\
\hline Swerdon et al. [21] & 2009 & Conference Paper & Air and land vehicle & theoretical concept & multiple & analytics \\
\hline Qamar et al. [22] & 2009 & Conference Paper & not specified & theoretical concept & multiple & analytics \\
\hline Dickerson and Valerdi [24] & 2010 & Conference Paper & Defense & prototype & multiple & synthesis \\
\hline Borutzky [25] & 2010 & Monography & not specified & theoretical concept & single & synthesis \\
\hline Follmer et al. [26] & 2010 & Conference Paper & not specified & theoretical concept & multiple & analytics \\
\hline Stetter et al. [27] & 2011 & Conference Paper & not specified & theoretical concept & multiple & synthesis \\
\hline Kleins et al. [28] & 2011 & Conference Paper & not specified & prototype & multiple & synthesis \\
\hline Witsch and Vogel-Heuser [29] & 2011 & Conference Paper & Production system & theoretical concept & multiple & synthesis \\
\hline Schütz and Vogel-Heuser [30] & 2011 & Other & Production system & theoretical concept & single & synthesis \\
\hline Piaszczyk [31] & 2011 & Other & Defense & theoretical concept & multiple & analytics \\
\hline Guan et al. [32] & 2012 & Journal Article & Air and land vehicle & theoretical concept & multiple & analytics \\
\hline Strahilov et al. [33] & 2012 & Conference Paper & Production systems & theoretical concept & multiple & analytics \\
\hline Magalhães et al. [34] & 2012 & Journal Article & Energy & theoretical concept & multiple & synthesis \\
\hline Hoffmann [35] & 2012 & Conference Paper & Other & theoretical concept & multiple & synthesis \\
\hline Ahn et al. [36] & 2012 & Conference Paper & Other & prototype & single & analytics \\
\hline Chandraiah and Dömer [37] & 2012 & Journal Article & Other & theoretical concept & single & synthesis \\
\hline Kim et al. [38] & 2012 & Conference Paper & Air and land vehicle & theoretical concept & multiple & analytics \\
\hline Schmelcher et al. [39] & 2012 & Conference Paper & Air and land vehicle & theoretical concept & multiple & synthesis \\
\hline Reichwein et al. [40] & 2012 & Conference Paper & not specified & theoretical concept & multiple & synthesis \\
\hline Follmer et al. [41] & 2012 & Conference Paper & not specified & theoretical concept & single & synthesis \\
\hline
\end{tabular}


Table 2. Cont

\begin{tabular}{|c|c|c|c|c|c|c|}
\hline Reference & Year & Type & Domain & Category & Multitude & Usage \\
\hline Ramos et al. [42] & 2012 & Conference Paper & Other & theoretical concept & multiple & synthesis \\
\hline Becherini et al. [43] & 2012 & Conference Paper & Space Technology & theoretical concept & single & analytics \\
\hline Glas and Sartorius [44] & 2012 & Conference Paper & Air and land vehicle & theoretical concept & multiple & analytics \\
\hline Ma et al. [46] & 2013 & Journal Article & Other & theoretical concept & single & analytics \\
\hline Zander [47] & 2013 & Conference Paper & Other & prototype & single & analytics \\
\hline Haveman and Bonnema [48] & 2013 & Conference Paper & Air and land vehicle & theoretical concept & multiple & synthesis \\
\hline Nattermann and Anderl [49] & 2013 & Conference Paper & Air and land vehicle & prototype & multiple & synthesis \\
\hline Gausemeier et al. [51] & 2013 & Journal Article & not specified & theoretical concept & multiple & synthesis \\
\hline Broy [52] & 2014 & Conference Paper & not specified & theoretical concept & single & analytics \\
\hline Barbieri et al. [53] & 2014 & Conference Paper & Production system & prototype & multiple & synthesis \\
\hline Zierolf et al. [54] & 2014 & Conference Paper & Air and land vehicle & theoretical concept & multiple & analytics \\
\hline Komoto et al. [55] & 2014 & Conference Paper & not specified & theoretical concept & multiple & synthesis \\
\hline Micouin [56] & 2014 & Journal Article & Air and land vehicle & theoretical concept & multiple & analytics \\
\hline Song et al. [57] & 2014 & Conference Paper & Other & theoretical concept & single & multiple \\
\hline Pfluegl et al. [58] & 2015 & Monography & Air and land vehicle & prototype & multiple & analytics \\
\hline Acker et al. [59] & 2015 & Conference Paper & Other & theoretical concept & multiple & analytics \\
\hline Morkevicius and Jankevicius [61] & 2015 & Conference Paper & Air and land vehicle & theoretical concept & multiple & analytics \\
\hline Tschirner et al. [62] & 2015 & Conference Paper & not specified & theoretical concept & multiple & analytics \\
\hline Kaslow [63] & 2015 & Conference Paper & Space Technology & theoretical concept & multiple & analytics \\
\hline Kaslow et al. [64] & 2015 & Conference Paper & Space Technology & theoretical concept & multiple & synthesis \\
\hline Holtmann et al. [65] & 2015 & Conference Paper & Air and land vehicle & theoretical concept & multiple & synthesis \\
\hline Dumitrescu et al. [66] & 2015 & Other & not specified & theoretical concept & multiple & synthesis \\
\hline Iwata et al. [67] & 2015 & Conference Paper & Space Technology & theoretical concept & single & analytics \\
\hline Hampson [68] & 2015 & Journal Article & not specified & theoretical concept & multiple & analytics \\
\hline Aboutaleb and Monsuez [69] & 2015 & Conference Paper & not specified & theoretical concept & multiple & synthesis \\
\hline Cheng and Zhou [70] & 2016 & Conference Paper & Energy & theoretical concept & multiple & analytics \\
\hline Johnson et al. [71] & 2016 & Journal Article & Other & theoretical concept & multiple & analytics \\
\hline Kulkarni et al. [72] & 2016 & Conference Paper & Space Technology & prototype & multiple & analytics \\
\hline Sindiy et al. [73] & 2016 & Conference Paper & Space Technology & existing business & multiple & synthesis \\
\hline Brecher et al. [74] & 2016 & Conference Paper & Production systems & theoretical concept & multiple & synthesis \\
\hline Vannesjo et al. [75] & 2016 & Journal Article & Other & theoretical concept & single & synthesis \\
\hline Henke et al. [76] & 2016 & Conference Paper & Production system & prototype & multiple & synthesis \\
\hline
\end{tabular}


Table 2. Cont

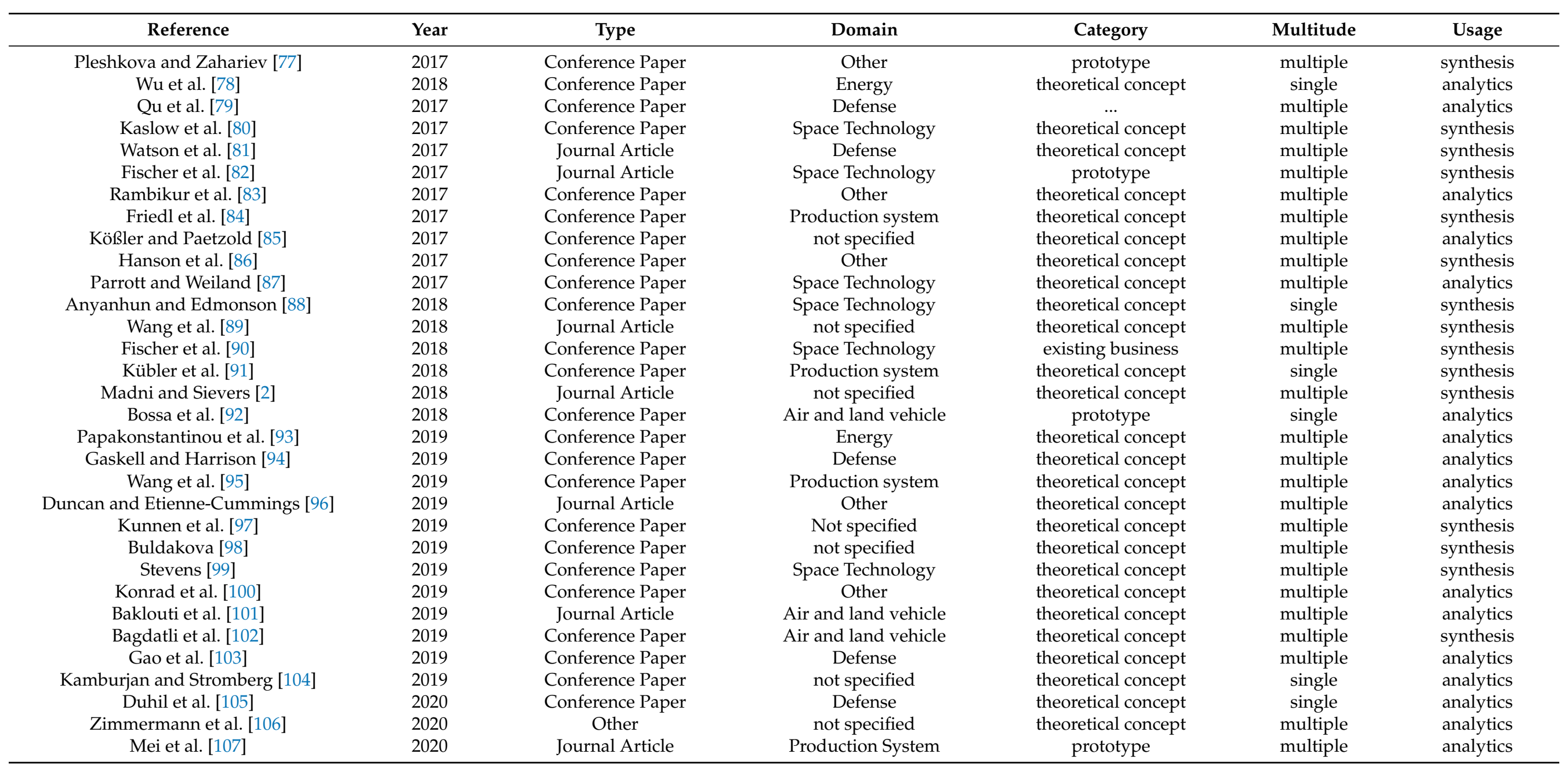


The chronological distribution of the 104 publications included is shown in Figure 4.
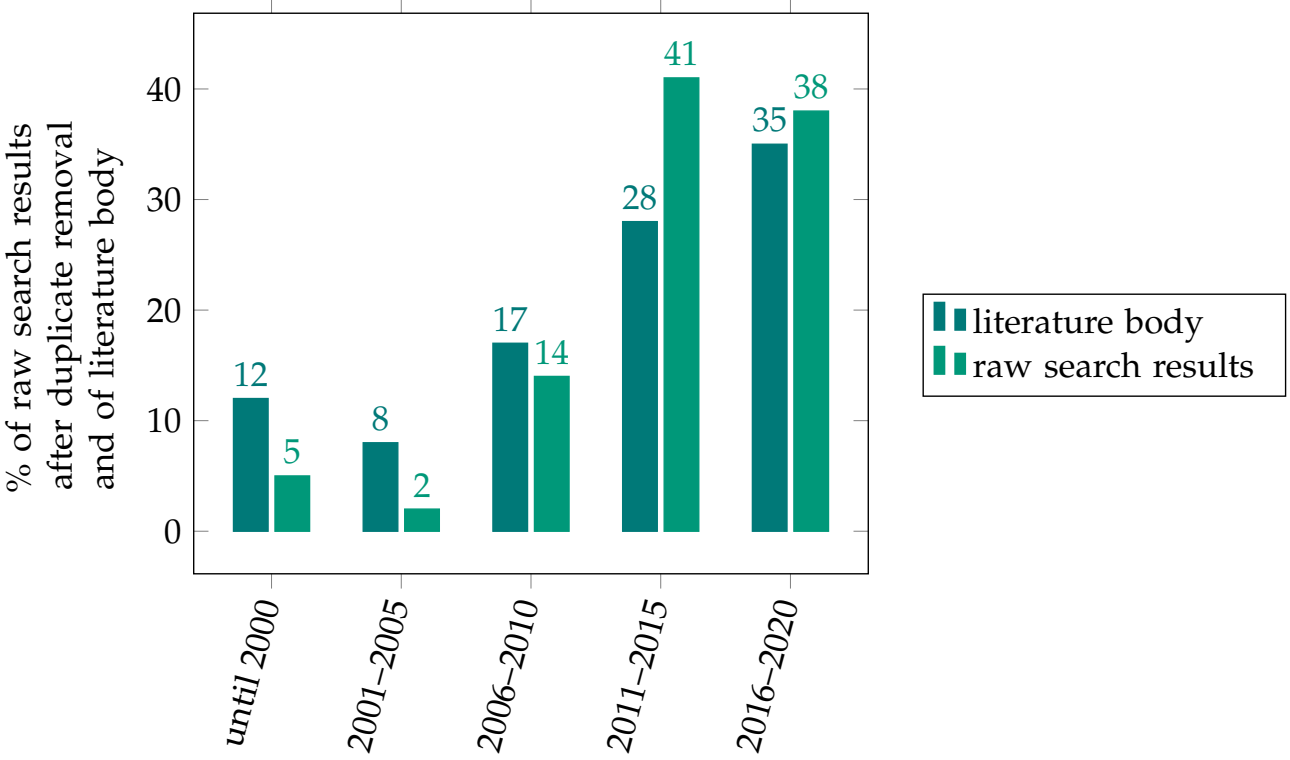

Figure 4. Chronological distribution of publications in raw search results and in literature body.

The earliest sample was published in 1977 as could be seen in Table 2. Despite the earliest sample being published in 1977, only about $12 \%$ of the raw search results were published before the year 2000, with only $5 \%$ of the publication in the literature body analyzed in-depth dating from before 2000.

Comparing the initial raw search results after duplicate removal with the body of literature analyzed in depth there is a considerable selection bias towards publications sources published 2011 or later.

Figure 5 displays this publication bias.

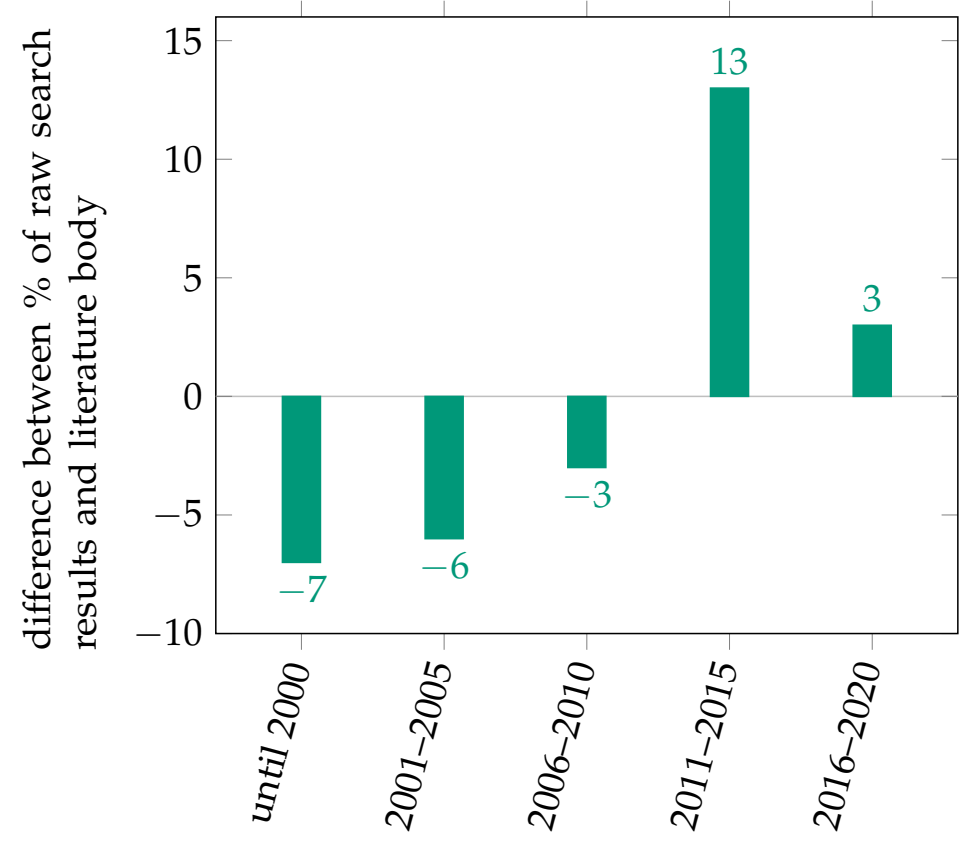

Figure 5. Comparison of actually included and raw search result data.

The largest amount of samples qualified for inclusion into the literature body dates from 2011 through 2015, despite this only being the second-largest bracket in terms of 
raw search results. At about $41 \%$ compared to a little under $38 \%$ this is of no significance given the sample size of $n=104$. What is more indicative of a shift towards the usage of the term 'system model' in the last decade is that, if combined, close to $80 \%$ of the publications included in the literature body were published in 2011 or later. This is largely driven by the fact that a significant amount of results before 2011 makes use of similar verbiage and concepts of systems theory but applies those concepts to natural systems, social systems, entirely mathematical problems or computer science topics. (Of those, a good amount offers great inspiration for novel systems engineering approaches and certainly deserves more attention from the engineering community, but do not qualify in the context of reviewing the definition and usage of systems models in systems engineering or for engineered systems in general.) We suspect this being overall related to advances in IT-infrastructure and tools available and in particular the increasing computing capabilities that allow for more intensive use of tracing between artifacts and data used as part of systems development and of simulation as part of system development and operation.

The domain of the target systems have been clustered in seven (7) categories: Space Technology, Production Systems, Air and Land Vehicle, Energy, Defense, Other and 'Not Specified'. The latter has been used when the solution was described as universally applicable or if a specific domain or target system could not be identified (e.g., if the aim of the publication was on the methodological approach). In context of the domain, 'Other' comprises diverse areas, such as communication, forestry, mechanical, embedded systems, control systems, complex System of Systems (SoS), building, Cyber-Physical System (CPS), computer engineering, robotics, biomedical and business process. The following Figure 6 depicts the distribution of these domains over the literature body.

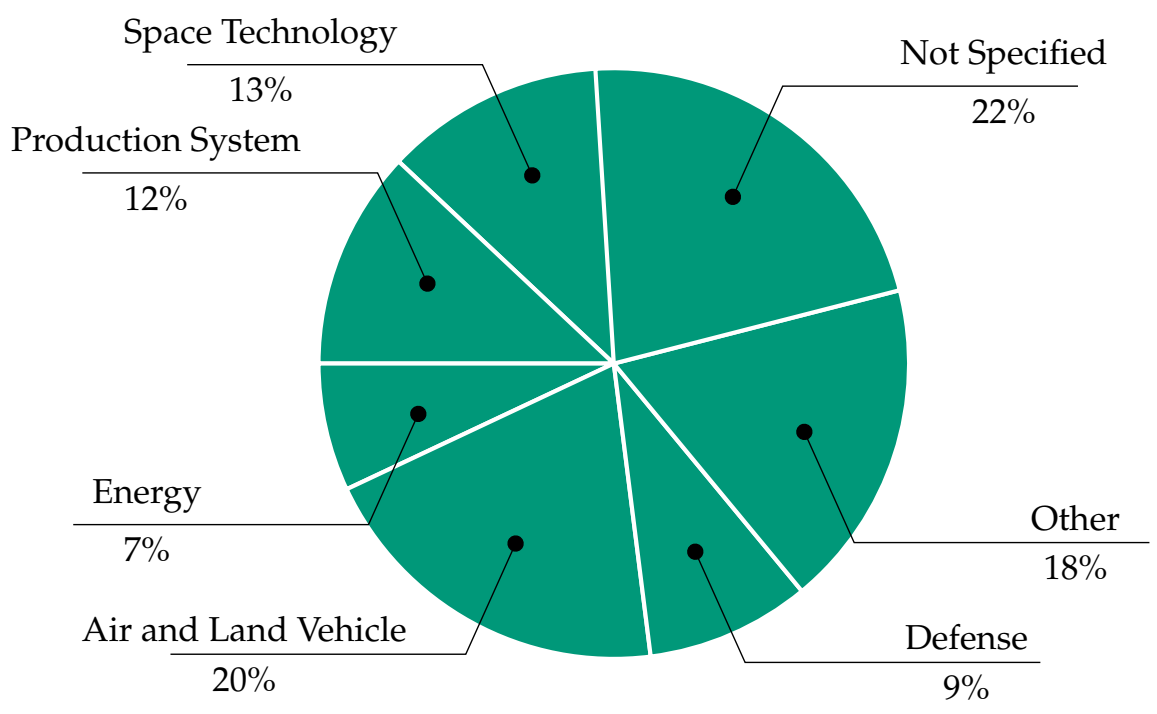

Figure 6. Distribution of publications in context of the investigated target system's domain.

With many publications of Systems Engineering (SE) focusing on Space and Aerospace, Space Technology and Air and Land Vehicle combined make up 33\% of all samples. Production systems (12\%), Energy (7\%) and Defense (9\%) combined make up less than $30 \%$ of the literature body. While the summed up other systems have an impact as well (18\%) the $22 \%$ of the not specified system show the use case-independent relevance of this topic.

For a breakdown of the use cases according to their maturity in the business model, we have divided them into the categories: Existing business, prototype, and theoretical concept. The latter refers to theoretical concepts based on existing business models that have not yet been implemented. Figure 7 displays their distribution. 


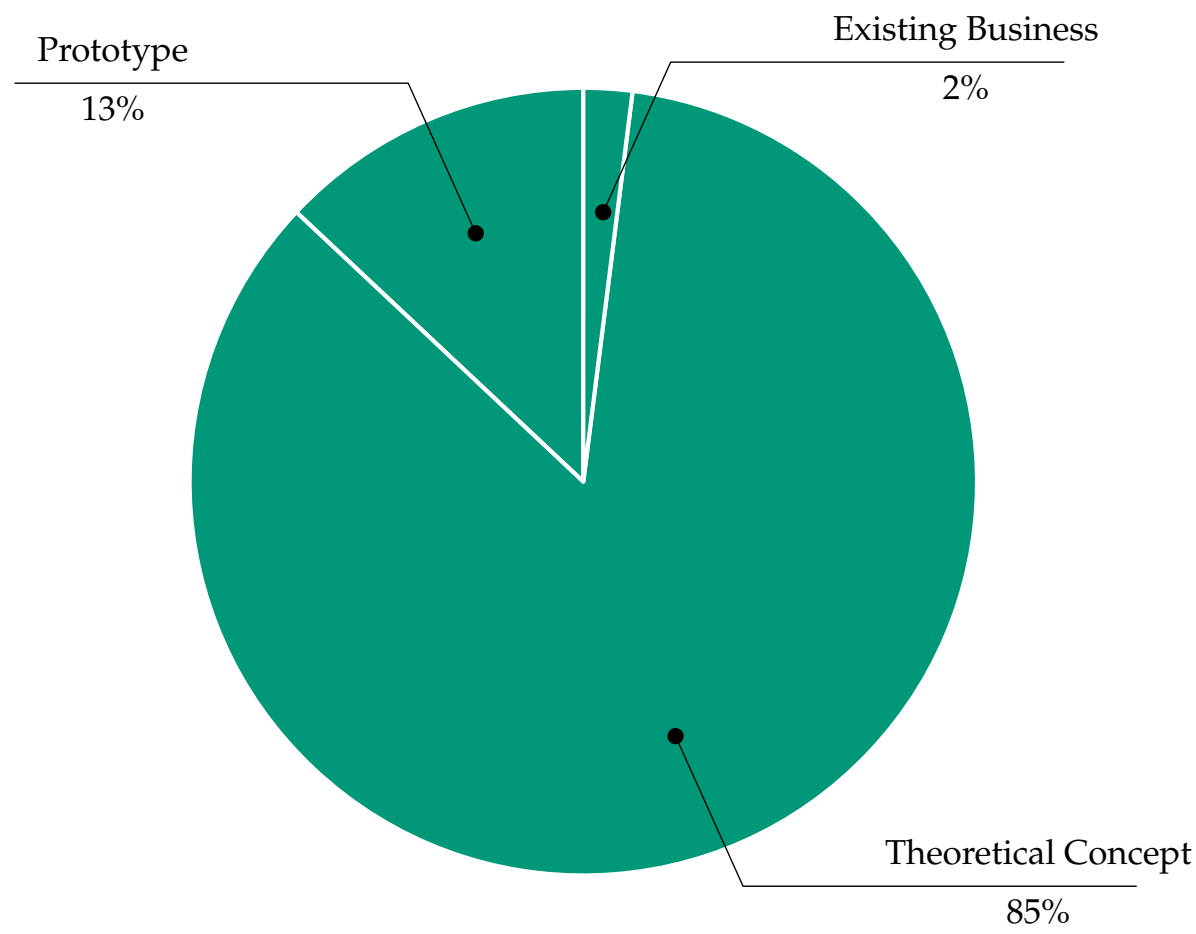

Figure 7. Distribution of maturity categories in literature body.

The largest part (85\%) of the literature body fall into the category "Theoretical Concept" and only $2 \%$ of the included publications cover the category "existing business" beyond mentioning currently applied methods and tools to the proposed new approaches to systems development. Overall, it is very noticeable that an overwhelming majority of $98 \%$ of samples fall into the categories "Theoretical Concept" or "Prototype". This may be explained by the fact that holistic system modeling is often either not applied to established system development processes or simply just not recognized as such, driven by the fact that organizations often develop system modeling capabilities over time and through a need-based bottom-up approach.

One question we tried to answer when we set out to review literature pertaining the definition and use of system models was whether there is a consensus if there can be more than one system model per system.

Most of the publications (72\%) refer to system models as a conglomerate of multiple models. In some cases (28\%) the term 'system model' is used for a specific type of model that can be used without further dependencies or related models.

The definition and purpose of the system model have been extracted from each publication as well. Due to readability, the table has been added to the Appendix A (Table A6). For each reference, the extracted key points for the purpose of the system model in the publication as well as the definition in sense of what is inside the model and how is it is created are listed there. The purpose has been clustered as synthesis and analytics in Table 2.

Both use cases, analysis and synthesis, make up roughly the same percentage with analytical use cases having a slightly larger share (51\%). To get a better insight, these aspects will be further investigated in the discussion part.

Regarding the definition of a 'system model' the distribution taken from Table A6 are listed in Figure 8.

The most widely used definition of a 'system model' are graphical language models defined with SysML or Object-Process Methodology (OPM) (44\%). $24 \%$ of the literature body call the combination of different domain-specific models a system model.Explicit domain models used for simulation like Matlab models are used in $14 \%$ of the literature body when speaking of 'system models'. Eventually, pure mathematical models as differ- 
ential equation (DEQ) systems and data models are meant in $10 \%$ and $4 \%$ of the literature body, respectively.

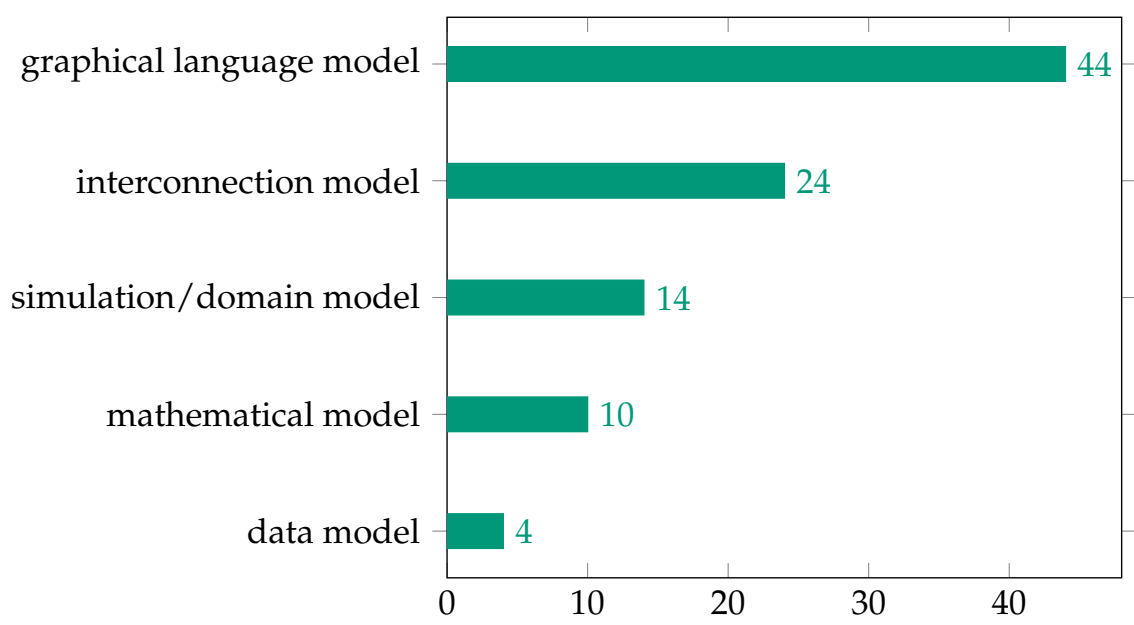

Figure 8. Number of definitions used in literature body (multiple assignments possible).

While most publications regarding graphical language models had references to MBSE, the publications presenting mathematical models and domain models did often not mention MBSE at all.

Figure 9 displays the dominant model formats for these definitions.

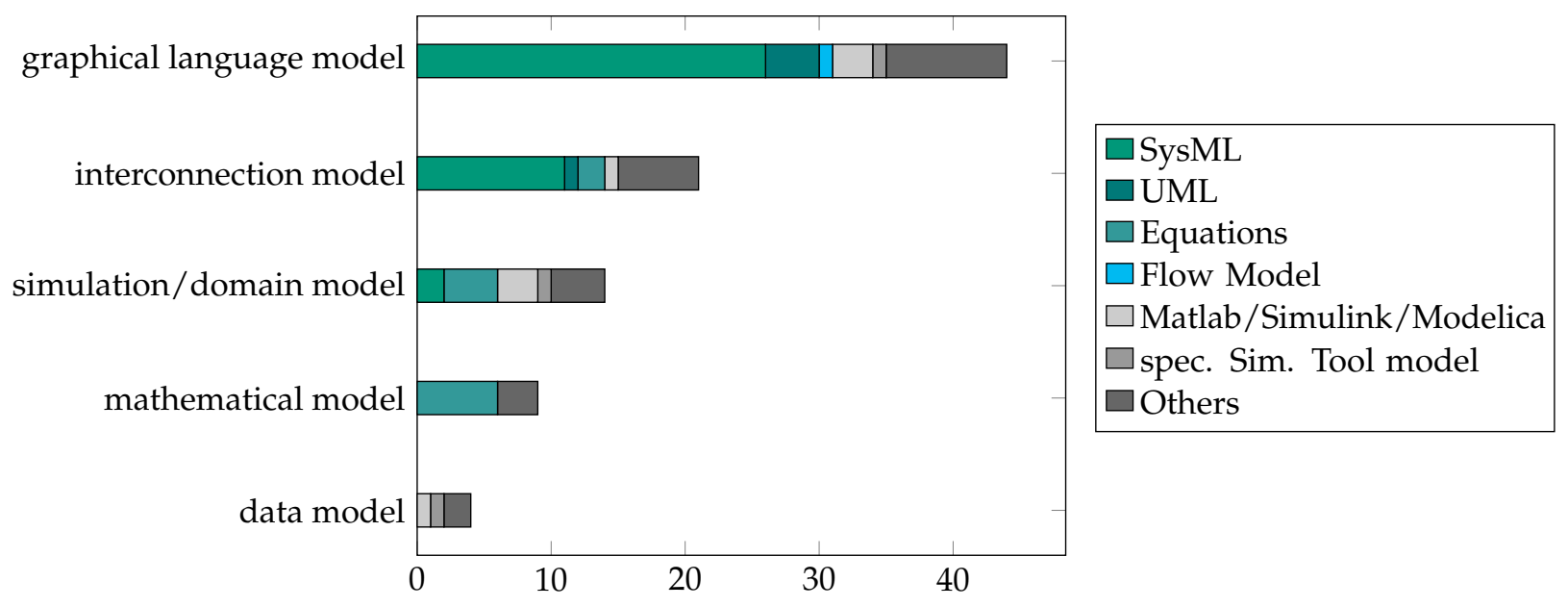

Figure 9. Number of model types per definition in literature body (multiple assignments possible).

Regarding the primary model format a publication utilizes there is a wide variety of custom or commercial tools and formats and only very few formats are used in more than three samples. SysML and Matlab/Simulink or Modelica are the dominant ones across all systems model definitions. Analyzing the primary model formats used in publications in correlation to their understanding of system models shows that multiple samples depict graphical modeling as the main aspect of systems modeling, but utilize Matlab/Simulink or Modelica as the primary model format. This is mainly caused by the fact that a large part of the publications describing graphical modeling as the core of a systems model, connect various behavior models through graphical diagrams.

As MBSE is largely driven by Software Engineering, the distribution of software systems as target system, compared to interdisciplinary systems has been investigated and is shown in Figure 10. 


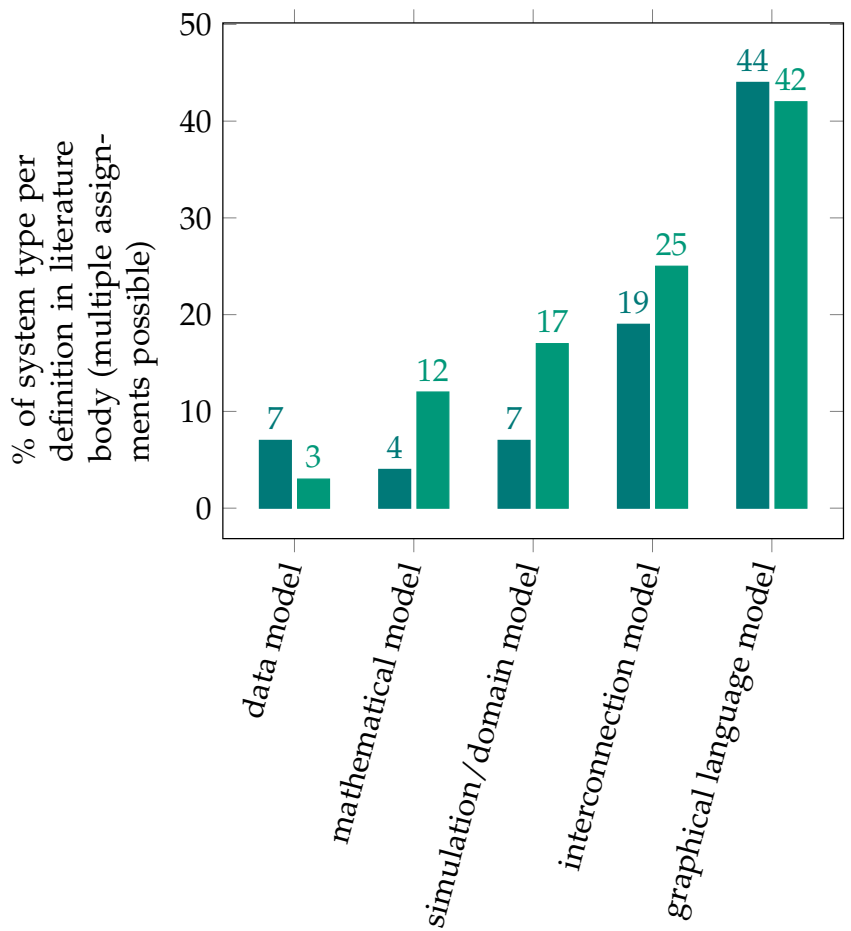

\author{
11 Software system \\ II Interdisciplinary system
}

Figure 10. Distribution of system type per definition (multiple assignments possible).

The distinction between publications that focus on the information system or softwaredriven aspects of their system of interest on one hand or the entire system across all domains equally on the other hand, interestingly does not show huge discrepancies in the respective understanding of system models. Data Models as the focus of systems modeling are significantly more common in software-centric publications compared to more holistic ones. The samples that consider the entire system equally put more emphasis on domainspecific simulation models, as well as general mathematical approaches like networks of differential equations. This is mostly driven by a stronger need to find generic approaches to combine multiple viewpoints and system aspects, while from a software-centric view behavior and data models are often sufficient.

\title{
4. Discussion
}

The results presented in the previous section shall be used to answer the research questions and validate the working hypotheses.

In this section, we discuss the results of our literature review.

\subsection{Definition of the Term 'System Model'}

As was expected, most publications referred to system models as graphical models like SysML and OPM models (Figure 8), which are often associated with MBSE. Furthermore, system models have been defined as mathematical models in form of DEQs, domainspecific models like Matlab models and as networks of multiple domain models. The definition data model was barely mentioned and therefore was included in the definition 'interconnected models', as data models were exclusively mentioned in the context of connecting multiple models.

Even though the domain-specific and mathematical models rarely mention MBSE, it is still seen as feasible for the modeling a complex engineered system. Therefore, they remain relevant within the context of systems modeling of technical systems.

Additionally, all system models have been digital. While models, in general, do not have to be virtual (e.g., clay models), digital representations that allow for different views on a model and the dynamic integration of different artifacts as system parameters provide great benefits. 


\subsection{Usage of the Term 'System Model'}

In regards to the use of system models, $51 \%$ of sources indicate a primary use of system models in the context of their publication as analytics, as opposed to $49 \%$ of publications that indicate system synthesis as the main driver behind the application of system modeling. According to our observations, this unclear picture is largely driven by the nature of systems development in engineering. Due to the recursive and iterative nature of system development, simulations as an aspect of system analytics generate knowledge about a current or future system, yet might ultimately be driven by system synthesis. This circular dependency between analytics and synthesis also means that the results obtained are usually applied to further develop and optimize a system until a desired system maturity and layout is achieved through multiple iterations. This usage is not bound to a single domain but is widely spread as could be seen in Figure 6 .

One question we tried to answer when we set out to review literature pertaining the definition and use of system models was whether there is consensus if there can be more than one 'system model' per system. It turned out that even within individual publications determining whether a single or multiple system models are being developed or applied is very difficult, due to the generally iterative and recursive nature of system development. None of the selected publications put much emphasis on this question either. The first issue here may be the vague definition of what constitutes a single model versus a group of highly interconnected models. For example, there is not even consensus on a technical level whether multiple diagrams in a graphical modeling notation constitute one model or multiple ones. This, again, may be attributed to the fact that system modeling is often applied from a need-driven perspective and ultimately it is probably not important as long as project/product boundaries are predetermined and the selected modeling approach supports existing or prospective use cases. This is further supported by the fact that none of the analyzed publications explicitly defines clear boundaries between pre-domain systems modeling and domain-specific modeling and development approaches. None of the samples attempts to even implicitly define a generalized definition of that predomain/domain boundary, which suggests that this boundary may be driven by existing processes and organizational structure and therefore be highly dependent on a specific use case. None of the reviewed publications contains negative views on system models, despite some samples mentioning new difficulties which arise with new methods and tools, such as requirements regarding IT-infrastructure, potentially new organizational structures as well as extended skill sets of developers. As conclusion, we found no consensus across the literature body, if there can be more than one 'system model' per system. Looking at the different definitions used in the publications (see Figure 8), there seems to be no evidence that there must not be more than one system model per system. In conclusion, this means that multiple system models per system should not be considered infeasible per se and might very well be useful depending on individual use cases.

\subsection{Drivers and Indicators for the Usage of System Models}

The decomposition of the statements on the reasons for applying system models into indicators and drivers supports a cause-and-effect analysis between drivers of system model usage. This approach connects the question why system models are being considered (Drivers) with the question, which measures authors aim to invoke on a technical level in order to achieve what they set out to accomplish (Indicators). Since the body of literature is of the size $\mathrm{n}=104$, most publications mention only one driver (111 mentions of drivers and 143 mentions of indicators) and for readability, the numbers shown in the Figure 11 represent the share of the drivers and indicators mentioned in the publications over their respective sum in absolute numbers. The different indicators are comprised of clustered aspects of systems development in engineering, which are supposed to be optimized according to the publications contained in our body of literature. The drivers are comprised of system properties on one hand and perceived challenges across a systems development life cycle on the other hand. Potentially perceived challenges might trace back to the 
system or product properties, but there was no clear evidence for this in the analyzed set of publications. While beyond the scope of this review, the obvious fact that system development activities seek to produce a system that exhibits a set of desired properties, suggests that the drivers would ultimately all trace to the system or product properties (the "best" possible system). The flow within the figure highlights relationships between drivers and indicators. If, for example, a publication describes the impact of improved traceability and attributes this to the driver Collaboration, this is recorded as a relation and is displayed as a sankey flow in the figure. The width of each sankey flow connector correlates to the number of samples mentioning this driver-indicator relationship. This enables visual identification of the correlations between drivers and indicators, and indicates the frequency of occurrence in the literature body.

The drivers were aggregated to form groups from the sum of all identified drivers contained in the body of literature, which often used different verbiage but was alluding to the identical driver:

- $\quad$ System Complexity: By far the most important driver resulted from the focus of many publications on improving the development and operation of large and highly interconnected mechatronic or cyber-physical systems.

- Development Process: A large number of publications included in the body of literature indicated the development process itself as the main driver for the application of system models in order to maintain consistency across processes and methods that are themselves complex and can not be handled well without the extensive use of modeling.

- $\quad$ System Quality: This is perhaps the most basic of all mentioned drivers and refers to the quality properties of a developed system as opposed to the performance of its development lifecycle activities.

- System Design: This driver pertains to the functional properties of a system and is mentioned by publications that describe the development of new features and design solutions, which emerged using system modeling.

- System Safety: The publications that explicitly describe safety as one of the drivers behind the use of system models employ systems modeling as a means to derive safety engineering-related artifacts automatically (e.g., fault trees).

- System Validation: This driver relates explicitly to system validation activities.

- System Modularization: Publications that mention this driver view system modeling as a tool to improve system modularization in terms of clear and standardized system boundaries to support compatibility with other systems and sub-systems.

- $\quad$ System Security: This driver relates systems modeling to the development of secure systems.

- System Certification: The publications explicitly mentioning certification as a driver see system modeling not only as a means to satisfy other certification requirements, but also as a direct requirement by certification authorities.

- System Performance: This driver does not relate to the implementation of novel features but improvements in non-functional properties, like general efficiency of the system, uptime, or accuracy of an operation executed by the developed system.

- Collaboration: A number of publications mention general collaboration among developers or even all stakeholders as a driver. This often is related to the ease or efficiency of exchange of information and data between developers internally, as well as with customers and other external parties.

Indicators:

- Improved Modeling Quality: This indicator includes factors such as model fidelity and performance in other aspects.

- Earlier Testing and Validation: This relates to the front-loading of verification and validation activities. 
- Traceability: This includes explicit traceability, e.g., in a requirements engineering context, as well as (dynamic) modeling of connections inside and between models improved systems.

- Integration: This includes aspects such as (co-) simulation and other digital methods that allow for front-loading and concurrent execution of integration activities.

- Better Requirements: This indicator relates to improved requirements in terms of the formal quality of the developed requirements and their usefulness for other aspects of system development.

- Improved Tools and Methods: This comprises improved IT-Tools and methods enabled by the application of systems modeling.

- Compliance: This indicator indicates a direct requirement to apply systems modeling by certification bodies or legal frameworks.

- Better Solution Architecture: An improved solution architecture relates to an improved system in terms of features available and/or system performance through new structural or behavioral properties that emerged using systems modeling.

- Intellectual Property (IP): This indicator relates to the way that system models can support the protection of intellectual property, in this particular case through compartmentalization of IP and easier exchange of subsystem models.

System Quality: 31

Validation: 4

- Intellectual Property: 1

improved model performance: 43

Complexity: 41

earlier testing and validation: 22

Development Process: 38

improved traceability: 27

Collaboration: 9

Improved Systems Integration: 18

System Performance: 9

Better Requirements: 5

- Safety: 4

Improved Digital Assistance: 12

System Design: 9

- System Modularization: 4

- Certification: 1

- Security: 1

better architecture: 11

improved compliance: 14

Figure 11. Sankey-flow chart with drivers depicted on the left side and indicators on the right.

Our analysis shows that the general challenge of development processes, system quality and system complexity are the main drivers for the application of system models (combined those three alone amounts to more than $73 \%$ of all mentions). These three are not necessarily independent criteria and over the course of our review, we come to conclude that the main reason development processes are perceived as challenging is often a combination of system complexity and the complexity of processes and tools. This would suggest that managing complexity and achieving high quality are the key drivers for the use of system modeling. The fact that complexity is a vaguely defined term in the context of systems engineering appears to show a relatively equal distribution of connections to all 
mentioned indicators. The three largest drivers System Complexity, Development Process and System Quality account for an overwhelming majority among the drivers. They are associated with almost all indicators to equal amounts (with the exception of System Quality being biased towards improved model performance), which may be because system development of large and interconnected systems poses a particular challenge with wide-ranging impact. This is because it comprises various activities and technical goals, which need to be managed and balanced in order to create the desired system or at least approximate the ideal outcome as closely as possible with available resources and under the current circumstances.

Overall, our analysis shows that system models are viewed as a sufficient tool to synthesize and analyze technical systems across various industries and domains, despite being seen as novel and to a degree often still experimental. A precise definition of the term system model remains elusive, yet there are certain key aspects in regards to the purpose system modeling should serve, that we were able to extract. Overall system modeling is applied to manage complexity in system development and unify as well as align different domains of system development. Depending on the author's perspective and the context, this can manifest itself as improved consistency, improved communication, improve collaboration or other terms that all describe a concerted effort by an organization to develop a technical system. For practitioners in engineering, the issue of system modeling and specifically how to utilize a system model is largely need-driven, without much emphasis on the definitions and boundaries that are of potential interest to academia and systems theory research. This becomes even more clear when considering the relative variety of implied definitions of the term system model. This need-driven and basically problem-solving-oriented view in the industry appears to also be reinforced by a largely bottom-up approach to systems modeling. Across all industries, explicit generic system modeling efforts through graphic modeling languages such as SysML, OPM and others are gaining traction, which are often associated with MBSE. Regarding incorporating behavioral and dynamic system characteristics, though, the architectures encountered in the body of literature draw significantly from established methods and models used in different engineering domains. For both modeling solution vendors as well as engineers ultimately only the outcome matters.

Due to the need-based and often bottom-up approach to system modeling in engineering, there is a considerable risk of missing publications that simply make use of different verbiage to describe their understanding of system models and their applications. Furthermore, non-peer-reviewed engineering magazines could contain more information regarding the use and understanding of system models in different industries, but those sources were mostly not searchable or otherwise indexed and were not included in the initial key word search.

This review sought to lower this risk by using a relatively wide range of keywords and putting more emphasis on manual review of a larger literature body. Across the body of the literature review, a wide range of either, very explicit or implicit statements were made regarding system models, their purpose, definition, general usage as well as unique use cases described. Quite often defining and describing the system model is not the main focus of publications and systems modeling is merely established and described as a solution to a problem, which is then described in further detail.

In addition to information about the scope of the review being embedded within other subjects of research in engineering and technology, some publications mentioned keywords of our search exclusively in their abstract without mentioning them in the actual text, or if so, only implicitly and hard to extract through automated methods, which was another driver for our focus on manual review of a less exclusive body of literature as opposed to a very restrictive keyword search. 


\subsection{Validation of Hypotheses}

Considering these discussion points, the hypotheses defined in the beginning shall be summarized and validated.

Hypothesis 1. There is yet no converged overall definition of the term 'system model': As most publications used different definitions for a 'system model', this hypothesis was confirmed. The definition presented by Hart [3] in Section 1 was the only full definition of a system model, even though it has not been referenced in any publication.

Hypothesis 2. A 'system model' can be created in different ways and is not limited to the application of Systems Modeling Language (SysML): This hypothesis was confirmed. System models are often created with and thus connected to graphical modeling languages like SysML, but are not limited to them. Mathematical modeling and direct linking of different models are also valid forms of system modeling.

Hypothesis 3. The usage of a 'system model' is not limited to the domain of System Engineers: This hypothesis was true considering all kinds of system models defined in the previous subsections. As one kind of system model may be domain-specific, different other domains can use them. With interconnection models and data models as system models domain-specific engineers can use them as well in their common tools, even though it is in an indirect form. Thus, system models can benefit all domains that are part of the system development.

The three confirmed hypotheses support and enrich Hart's [3] definition.

Definition 1. A system model is a (usually virtual) representation of the target system or one or more of its subsystems. It can be in the form of

(A) a domain specific part of the (sub)system (e.g., a domain-specific simulation model of a subsystem),

(B) a domain-independent structure of the (sub)system (e.g., system architecture) or

(C) a model linking the various (sub)system artifacts.

One key aspect of this definition is that in contrast to the definition of Hart [3], it specifically includes subsystems. In the previous definition, overall system interconnections were already addressed, but did not focus on the lower levels which have an important role. Additionally, domain-specific parts of systems and subsystems as well as models for linking artifacts, are included in this definition. The categorization within the definition allows us to classify upcoming research to one of these categories and thus allow an even better alignment of research conducted in that field.

\section{Conclusions}

Defining the term 'system model' is particularly challenging, considering the fact that there are multiple definitions for the concepts 'system' and 'model', which are not always consistent. Despite there being a vague general agreement as to what those terms mean, the general understanding is not clear enough to establish a definitive scope of system modeling and system models in engineering and technology.

Across various industries, as much as it seems clear what purpose system models serve on a higher level, it remains unclear where system modeling ends and where domainspecific methods and models begin. This makes it particularly difficult to define an exclusive scope of systems modeling in engineering and technology.

There is also no consensus in the reviewed publications regarding the ideal system modeling approach (a perfect generic solution presumably does not exist) there is a broad consensus about the benefits and the need for system models. In general, the utilization of systems modeling is driven by business needs and largely tailored to specific challenges system developers face, when engineering a particular system. This use-case-driven approach does neither require a general definition of the 'system model' nor a clear distinction 
between what constitutes a system model and what does not. Innovations appear therefore mostly driven by use-case studies and experiments as opposed to an overall theory of system modeling in engineering. More academia and research-driven publications looking to improve on current advances and to innovate current system development approaches, attempt to apply existing concepts from other modeling domains, such as Software Engineering. In those samples, systems theory concepts are additionally leveraged to support evidence-based knowledge with a more mathematical and rule-based foundation. Often this is part of a greater effort in further defining and developing MBSE beyond high-level approaches or the mere application of specific methods that are supposed to support model-based approaches to systems engineering.

Author Contributions: Conceptualization, M.M.S. and T.C.Z.; methodology, M.M.S.; formal analysis, T.C.Z.; investigation, M.M.S. and T.C.Z.; data curation, T.C.Z.; writing_original draft preparation, M.M.S.; writing_review and editing, T.C.Z.; visualization, M.M.S.; supervision, R.S. All authors have read and agreed to the published version of the manuscript.

Funding: This research received no external funding.

Conflicts of Interest: The authors declare no conflict of interest.

\section{Abbreviations}

The following abbreviations are used in this manuscript:

$\begin{array}{ll}\text { API } & \text { Application Programming Interface } \\ \text { BN } & \text { Bayesian network } \\ \text { BPMN } & \text { Business process model and notation } \\ \text { CPS } & \text { Cyber-Physical System } \\ \text { DEQ } & \text { differential equation } \\ \text { DHS } & \text { Distributed heterogenous simulation } \\ \text { DSL } & \text { Domain specific language } \\ \text { DSM } & \text { Descriptive System Model } \\ \text { FAD } & \text { Function analysis diagram } \\ \text { FEA } & \text { Finite Element Analysis } \\ \text { FMEA } & \text { Failure Mode and Effect Analysis } \\ \text { IDEF0 } & \text { Integration Definition for Function Modeling } \\ \text { IEEE } & \text { Institute of Electrical and Electronics Engineers } \\ \text { INCOSE } & \text { International Counsil on Systems Engineering } \\ \text { IML } & \text { Interdisiplinary modeling language } \\ \text { MDPI } & \text { Multidisciplinary Digital Publishing Institute } \\ \text { MES } & \text { Manufacturing Execution System } \\ \text { MBSE } & \text { Model-Based Systems Engineerging } \\ \text { OPM } & \text { Object-Process Methodology } \\ \text { PRISMA } & \text { Preferred Reporting Items for Systematic Reviews and Meta-Analyses } \\ \text { SE } & \text { Systems Engineering } \\ \text { SETR } & \text { Systems engineering technical review } \\ \text { SoS } & \text { System of Systems } \\ \text { SysML } & \text { Systems Modeling Language } \\ \text { UML } & \text { Unified Modeling Language } \\ \text { V\&V } & \text { Validation and Verification } \\ & \end{array}$


Appendix A. Tables

Table A1. Used keywords—Scopus.

\begin{tabular}{llrl}
\hline Database & Keyword & Count & Search String \\
\hline Scop-1 & federated system model & 45 & TITLE-ABS-KEY (federated AND "system model") \\
Scop-2 & system model creation & 499 & TITLE-ABS-KEY ("system model" AND creation) \\
Scop-3 & system model development & 130 & TITLE-ABS-KEY ("system model development") \\
Scop-4 & system model usage & 642 & TITLE-ABS-KEY ("system model” AND usage) \\
Scop-5 & system model fidelity & 458 & TITLE-ABS-KEY ("system model" AND fidelity) \\
Scop-6 & system model complexity & 14 & TITLE-ABS-KEY ("system model complexity") \\
Scop-7 & system model uncertainty & 114 & TITLE-ABS-KEY ("system model uncertainty") \\
Scop-8 & multi-model networks & 7 & TITLE-ABS-KEY ("multi-model network") \\
Scop-9 & model hierarchy & 11 & TITLE-ABS-KEY ("model hierarchy") \\
Scop-10 & system model perspectives & 19 & TITLE-ABS-KEY ("system model perspective") \\
Scop-11 & system model visualization & 469 & TITLE-ABS-KEY ("system model" AND visualization) \\
Scop-12 & system model characteristics & 8 & TITLE-ABS-KEY ("system model characteristic") \\
Scop-13 & transdisciplinary system model & 21 & TITLE-ABS-KEY (transdisciplinary AND "system model") \\
Scop-14 & interdisciplinary system model & 242 & TITLE-ABS-KEY (interdisciplinary AND "system model") \\
Scop-15 & system model + MBSE & 155 & TITLE-ABS-KEY ("system model" AND mbse) \\
Scop-16 & system of systems model & 52 & TITLE-ABS-KEY ("system of systems model") \\
\hline
\end{tabular}

Table A2. Used keywords-Web Of Science.

\begin{tabular}{|c|c|c|c|}
\hline Database & Keyword & Count & Search String \\
\hline WebO-1 & federated system model & 21 & ALL $=($ federated AND "system model" $)$ \\
\hline WebO-2 & system model creation & 193 & ALL $=$ ("system model" AND creation) \\
\hline WebO-3 & system model development & 74 & $\mathrm{ALL}=($ "system model development") \\
\hline WebO-4 & system model usage & 278 & ALL $=($ "system model" AND usage $)$ \\
\hline WebO-5 & system model fidelity & 205 & ALL $=$ ("system model" AND fidelity) \\
\hline WebO-6 & system model complexity & 10 & ALL $=($ "system model complexity") \\
\hline WebO-7 & system model uncertainty & 25 & ALL $=($ "system model uncertainty") \\
\hline WebO-8 & multi-model networks & 679 & ALL $=$ ("multi-model" AND network) \\
\hline WebO-9 & model hierarchy & 217 & ALL $=($ "model hierarchy") \\
\hline WebO-10 & system model perspectives & 604 & ALL $=($ "system model" AND "perspective") \\
\hline WebO-11 & system model visualization & 170 & ALL $=($ "system model" AND "visualization") \\
\hline WebO-12 & system model characteristics & 671 & ALL $=$ ("system model" AND "characteristic") \\
\hline WebO-13 & transdisciplinary system model & 17 & ALL $=($ "transdisciplinary" AND "system model") \\
\hline WebO-14 & interdisciplinary system model & 228 & ALL $=($ "interdisciplinary" AND "system model") \\
\hline WebO-15 & system model + MBSE & 87 & $\begin{array}{l}\text { ALL = ("system model" AND ("MBSE" OR } \\
\text { "Modelbased Systems Engineering" OR } \\
\text { "Model-Based Systems Engineering" OR } \\
\text { "Model Based Systems Engineering")) }\end{array}$ \\
\hline WebO-16 & system of systems model & 339 & $\begin{array}{l}\text { ALL = ("system-of-systems model" OR } \\
\text { "system of systems model" OR } \\
\text { "systems of systems models" OR } \\
\text { "sytems-of-systems model" OR "SoS model") }\end{array}$ \\
\hline
\end{tabular}


Table A3. Used keywords-Sage.

\begin{tabular}{llrl}
\hline Database & Keyword & Count & Search String \\
\hline Sage-1 & federated system model & 22 & [Abstract "system model"] AND [Abstract federated] \\
Sage-2 & system model creation & 35 & [Abstract "system model"] AND [Abstract creation] \\
Sage-3 & system model development & 210 & [Abstract "system model"] AND [Abstract development] \\
Sage-4 & system model usage & 347 & [Abstract "system model"] AND [Abstract usage] \\
Sage-5 & system model fidelity & 4 & [Abstract "system model"] AND [Abstract fidelity] \\
Sage-6 & system model complexity & 75 & [Abstract "system model"] AND [Abstract complexity] \\
Sage-7 & system model uncertainty & 47 & [Abstract "system model"] AND [Abstract uncertainty] \\
Sage-8 & multi-model networks & 4 & [Abstract "multi-model"] AND [Abstract network] \\
Sage-9 & model hierarchy & 3 & [Abstract "model hierarchy"] \\
Sage-10 & system model perspectives & 14 & [Abstract "system model"] AND [Abstract perspective] \\
Sage-11 & system model visualization & 2 & [Abstract "system model"] AND [Abstract visualization] \\
Sage-12 & system model characteristics & 93 & [Abstract "system model"] AND [Abstract characteristic] \\
Sage-13 & transdisciplinary system model & 0 & [Abstract "system model"] AND [Abstract transdisciplinary] \\
Sage-14 & interdisciplinary system model & 2 & [Abstract "system model"] AND [Abstract interdisciplinary] \\
Sage-15 & system model + MBSE & 0 & [Abstract "system model"] AND [MBSE] \\
Sage-16 & system of systems model & 0 & [Abstract "system of systems model"] \\
\hline
\end{tabular}

Table A4. Used keywords-IEEExplore.

\begin{tabular}{llrl}
\hline Database & Keyword & Count & Search String \\
\hline IEEE-1 & federated system model & 19 & ("All Metadata": federated AND "system model") \\
IEEE-2 & system model creation & 88 & ("All Metadata": "system model" AND creation) \\
IEEE-3 & system model development & 23 & ("All Metadata": "system model development") \\
IEEE-4 & system model usage & 184 & ("All Metadata": "system model" AND usage) \\
IEEE-5 & system model fidelity & 89 & ("All Metadata": "system model" AND fidelity) \\
IEEE-6 & system model complexity & 14 & ("All Metadata": "system model complexity") \\
IEEE-7 & system model uncertainty & 46 & ("All Metadata": "system model uncertainty") \\
IEEE-8 & multi-model networks & 264 & ("All Metadata": "multi-model" AND network) \\
IEEE-9 & model hierarchy & 69 & ("All Metadata": "model hierarchy") \\
IEEE-10 & system model perspectives & 203 & ("All Metadata": "system model" AND perspective) \\
IEEE-11 & system model visualization & 169 & ("All Metadata": "system model" AND visualization) \\
IEEE-12 & system model characteristics & 1 & ("All Metadata": "system model characteristic") \\
IEEE-13 & transdisciplinary system model & 3 & ("All Metadata": transdisciplinary AND “system model") \\
IEEE-14 & interdisciplinary system model & 38 & ("All Metadata": interdisciplinary AND "system model") \\
IEEE-15 & system model + MBSE & 52 & ("All Metadata": "system model" AND MBSE) \\
IEEE-16 & system of systems model & 49 & "All Metadata": "system-of-systems model" \\
& & & OR "system of systems model" OR \\
& & & "systems of systems models" OR \\
& & & "sytems-of-systems model" \\
& & & OR "SoS model") \\
\hline
\end{tabular}


Table A5. Used keywords—arXive.org.

\begin{tabular}{|c|c|c|c|}
\hline Database & Keyword & Count & Search String \\
\hline arXi-1 & federated system model & 7 & all:federated + AND + all:\%22system + model $\% 22$ \\
\hline arXi-2 & system model creation & 9 & all:creation + AND + all:\%22system + model $\% 22$ \\
\hline $\operatorname{arXi-3}$ & system model development & 448 & all:development + AND + all:\%22system + model $\% 22$ \\
\hline arXi-4 & system model usage & 14 & all:usage + AND + all: $\% 22$ system + model $\% 22$ \\
\hline arXi-5 & system model fidelity & 17 & all:fidelity + AND + all:\%22system + model $\% 22$ \\
\hline arXi-6 & system model complexity & 356 & all:complexity + AND + all:\%22system + model $\% 22$ \\
\hline $\operatorname{arXi-7}$ & system model uncertainty & 128 & all:uncertainty + AND + all:\%22system + model $\% 22$ \\
\hline arXi-8 & multi-model networks & 41 & all:network + AND + all:\%22multi + model $\% 22$ \\
\hline arXi-9 & model hierarchy & 33 & all:\%22model + hierarchy $\% 22$ \\
\hline arXi-10 & system model perspectives & 49 & all:perspective + AND + all:\%22system + model $\% 22$ \\
\hline arXi-11 & system model visualization & 36 & all:visualization + AND + all:\%22system + model $\% 22$ \\
\hline arXi-12 & system model characteristics & 116 & all:characteristics + AND + all:\%22system + model $\% 22$ \\
\hline arXi-13 & transdisciplinary system model & 0 & all:transdisciplinary + AND + all:\%22system + model $\% 22$ \\
\hline arXi-14 & interdisciplinary system model & 2 & all:interdisciplinary + AND + all:\%22system + model\%22 \\
\hline arXi-15 & system model + MBSE & 0 & all:MBSE + AND + all:\%22system + model $\% 22$ \\
\hline arXi-16 & system of systems model & 3 & $\begin{array}{l}\text { all:\%22system-of-systems + model } \% 22+\mathrm{OR}+\text { all:\%22system }+ \\
\text { of+systems+model } \% 22\end{array}$ \\
\hline
\end{tabular}

Table A6. Purpose and definition of system models extracted from eligible literature.

\begin{tabular}{|c|c|c|}
\hline Reference & Definition & Purpose \\
\hline Capehart [5] & system of differential equations & create continuous computer simulation \\
\hline Joshi et al. [6] & state graphs connecting models & connection with physical models \\
\hline Ironmonger et al. [7] & $\begin{array}{l}\text { Object-Oriented database management } \\
\text { system }\end{array}$ & controlling \\
\hline Bluff [8] & $\begin{array}{l}\text { link between behavior model and } \\
\text { performance model, should aim to provide } \\
\text { architecture optimization }\end{array}$ & $\begin{array}{c}\text { Analyze hardware and software components } \\
\text { and their interaction, early understanding of } \\
\text { system behavior in operation }\end{array}$ \\
\hline Bluff [9] & $\begin{array}{l}\text { link between behavior model and } \\
\text { performance model, should aim to provide } \\
\text { architecture optimization }\end{array}$ & $\begin{array}{l}\text { Analyze hardware and software components } \\
\text { and their interaction, early understanding of } \\
\text { system behavior in operation }\end{array}$ \\
\hline Estanbouli et al. [10] & mathematical model (equations) & analysis, easier form of FEA \\
\hline Hicks et al. [11] & $\begin{array}{l}\text { system architecture that is progressively fed } \\
\text { with details until a network of mathematical } \\
\text { components is achieved }\end{array}$ & $\begin{array}{l}\text { developing architectures comprised of } \\
\text { standard components }\end{array}$ \\
\hline Wilson et al. [12] & $\begin{array}{l}\text { captures logic of knowledge in a graphical } \\
(\mathrm{BN}) \text { and mathematical model }\end{array}$ & $\begin{array}{l}\text { provides a big picture of the system's } \\
\text { functionality that can form the basis for a } \\
\text { statistical analysis }\end{array}$ \\
\hline Che and Jennings [13] & $\begin{array}{l}\text { any kind of system, subsystem or component } \\
\text { with behavior representation that can be } \\
\text { shared with other developers and connected } \\
\text { with their respective models }\end{array}$ & $\begin{array}{l}\text { integrated system representation from } \\
\text { requirement through behavioral component } \\
\text { models }\end{array}$ \\
\hline Ma et al. [14] & block model & system operation and optimization \\
\hline Curry et al. [15] & $\begin{array}{l}\text { graphical and mathematical model (parameter } \\
\text { model network, linear programming model) }\end{array}$ & quantify system capacity, getting alternatives \\
\hline Sturm [16] & UML model & provide multiple views on the system \\
\hline Wakefield and Miller [17] & $\begin{array}{l}\text { center of development process, simulation } \\
\text { model of a process }\end{array}$ & $\begin{array}{l}\text { design of complex algorithms combined with } \\
\text { hardware, system simulation }\end{array}$ \\
\hline Amrhein et al. [18] & $\begin{array}{l}\text { combination of subsystem models (DHS) or } \\
\text { single models }\end{array}$ & $\begin{array}{l}\text { integrated system simulation and behavior } \\
\text { prediction }\end{array}$ \\
\hline Hoang et al. [19] & simulation models of integrated system & mitigate system risk, system test \\
\hline
\end{tabular}


Table A6. Cont.

\begin{tabular}{|c|c|c|}
\hline Reference & Definition & Purpose \\
\hline Hummel and Braun [20] & $\begin{array}{l}\text { integrated model based on multiple behavior } \\
\text { models defining components and ports }\end{array}$ & $\begin{array}{c}\text { quickly derive domain specific simulation } \\
\text { scenarios }\end{array}$ \\
\hline Swerdon et al. [21] & simulation model on component level & $\begin{array}{l}\text { diagnostics and health management, failure } \\
\text { mode analysis }\end{array}$ \\
\hline Qamar et al. [22] & $\begin{array}{c}\text { models defined with system modeling } \\
\text { languages (here SysML) }\end{array}$ & $\begin{array}{l}\text { investigate design alternatives, check quality } \\
\text { of design, resolving complexity by } \\
\text { transformation of information, simulation (in } \\
\text { combination with other tools, e.g., Matlab) }\end{array}$ \\
\hline Li and Xiong [23] & connected models of application and behavior & $\begin{array}{l}\text { understanding of possible operation-design } \\
\text { space exploration }\end{array}$ \\
\hline Dickerson and Valerdi [24] & basic attributes of the system, graphical model & tracing and model transformation to SoS \\
\hline Borutzky [25] & $\begin{array}{c}\text { an interconnection of system components, } \\
\text { an aggregation of data and methods operating } \\
\text { on them }\end{array}$ & single source of truth and used for simulation \\
\hline Follmer et al. [26] & $\begin{array}{c}\text { domain-neutral models to bridge different } \\
\text { engineering domains, provide a holistic } \\
\text { system view and simulate overall system } \\
\text { behavior }\end{array}$ & describe complex system in holistic way \\
\hline Stetter et al. [27] & $\begin{array}{l}\text { model, holding cross domain information } \\
\text { about the system and important relations; } \\
\text { holds different types of knowledge }\end{array}$ & application of agent systems \\
\hline Kleins et al. [28] & UML diagrams & $\begin{array}{l}\text { build modeling tools and DSL for running } \\
\text { simulations }\end{array}$ \\
\hline Witsch and Vogel-Heuser [29] & $\begin{array}{l}\text { graphical modeling notation based on BPMN, } \\
\text { model of the technical system, describes } \\
\text { components of that system, static model }\end{array}$ & provide data for MES \\
\hline Schütz and Vogel-Heuser [30] & control of agents in agent based system & manually integrate model information \\
\hline Piaszczyk [31] & $\begin{array}{l}\text { graphically described model (IDEF0 or SysML } \\
\text { or similar) }\end{array}$ & $\begin{array}{l}\text { very early validation in cooperation with } \\
\text { stakeholders, generally front-loading }\end{array}$ \\
\hline Guan et al. [32] & $\begin{array}{l}\text { mathematically formalized model, does not } \\
\text { rely on structural architecture of the system }\end{array}$ & $\begin{array}{l}\text { used for hybrid simulation (virtual/real) } \\
\text { validation }\end{array}$ \\
\hline Strahilov et al. [33] & geometry, multi body system model & validation \\
\hline Magalhães et al. [34] & $\begin{array}{l}\text { tool for understanding and predicting the } \\
\text { performance of the trigeneration system as } \\
\text { well as sizing it }\end{array}$ & predict system performance, simulation \\
\hline Hoffmann [35] & $\begin{array}{l}\text { SysML models, relevant for systems } \\
\text { engineering (architecture etc,), mainly } \\
\text { executable, only mentions subsystem models }\end{array}$ & trade studies \\
\hline Ahn et al. [36] & mathematical equations, transform function & $\begin{array}{c}\text { Analysis of system (e.g., damping) and design } \\
\text { of system }\end{array}$ \\
\hline Chandraiah and Dömer [37] & $\begin{array}{l}\text { executable specification of the design on } \\
\text { system level }\end{array}$ & (automated) system exploration and synthesis \\
\hline Kim et al. [38] & $\begin{array}{l}\text { generated with graphical modeling (here } \\
\text { SysML), descriptive, not analytical by default }\end{array}$ & $\begin{array}{l}\text { automatically generate analytical models and } \\
\text { execute them, connected to anayltical model }\end{array}$ \\
\hline Schmelcher et al. [39] & $\begin{array}{l}\text { contains cross-domain information and } \\
\text { relations, created here with SysML }\end{array}$ & $\begin{array}{l}\text { survey interdisciplinary information with } \\
\text { agent based systems, spanning framework for } \\
\text { further system development tools }\end{array}$ \\
\hline
\end{tabular}


Table A6. Cont.

\begin{tabular}{|c|c|c|}
\hline Reference & Definition & Purpose \\
\hline Reichwein et al. [40] & $\begin{array}{l}\text { SysML or Modelica (high level and } \\
\text { simulation) }\end{array}$ & $\begin{array}{l}\text { describe requirements etc (glsSysML), } \\
\text { descirbe and simulate dynamics and behavior } \\
\text { (Modelica) }\end{array}$ \\
\hline Follmer et al. [41] & $\begin{array}{l}\text { integrated model connecting a full system } \\
\text { model with sub system und domain models }\end{array}$ & $\begin{array}{l}\text { provide holistic cross domain view of system } \\
\text { and analyze overall reliability of the system, } \\
\text { connect abstract models with concrete models }\end{array}$ \\
\hline Ramos et al. [42] & $\begin{array}{l}\text { in SysML: requirements, its structure, its } \\
\text { behavior, its parametrics. This integrated } \\
\text { specification is usually in interaction with } \\
\text { other engineering models (e.g., simulation } \\
\text { models, analysis models, hardware models) }\end{array}$ & $\begin{array}{c}\text { single source of truth, defining system } \\
\text { boundaries }\end{array}$ \\
\hline Becherini et al. [43] & $\begin{array}{l}\text { static model of functions and elements of a } \\
\text { system }\end{array}$ & $\begin{array}{l}\text { to provide different views of systems and } \\
\text { subsequently used as basis for the derivation } \\
\text { of simulation models in a more mature stage } \\
\text { of product development }\end{array}$ \\
\hline Glas and Sartorius [44] & $\begin{array}{l}\text { SysML/UML model of capabilities, } \\
\text { parameters, system function, simulation, } \\
\text { unclear of individual UML artifacts are } \\
\text { system models too }\end{array}$ & $\begin{array}{c}\text { performance assessment and effort estimation; } \\
\text { sketching existing system for benchmarking } \\
\text { the to-be-designed system; explore design } \\
\text { alternatives }\end{array}$ \\
\hline Wang and Wang [45] & mathematical models (DEQ) & simulation \\
\hline Ma et al. [46] & $\begin{array}{l}\text { model of the enery consumption system, } \\
\text { multi-view model and mathematical model }\end{array}$ & efficiency assessment \\
\hline Zander [47] & executable simulation model of the system & simulation (compute states and outputs) \\
\hline Haveman and Bonnema [48] & high-level (pre-domain) model (here SysML) & $\begin{array}{c}\text { communicate information for design } \\
\text { trade-offs }\end{array}$ \\
\hline
\end{tabular}

contains requirements, functions, components

Nattermann and Anderl [49] and corresponding properties and parameters as well as their interdependencies, derived

communication across domains, simulation

from functions and requirements

Sharon et al. [50]

OPM model

partial models form the discipline-spanning system model. This system model is the starting point for the discipline-specific development of the product formally and model-based connection project management and product development

calculate the product maturity on system level, module level, domain level, and system element level, obtaining relevant information for planning the development progress are extracted from the system model and project management

\begin{tabular}{ccc}
\hline Broy [52] & Dymola models & Analysis of a system \\
\hline Barbieri et al. [53] & SysML model & $\begin{array}{c}\text { change analysis and linking domain specific } \\
\text { design }\end{array}$ \\
\hline Zierolf et al. [54] & software model & $\begin{array}{c}\text { simulation, understanding system level } \\
\text { behavior }\end{array}$ \\
\hline Komoto et al. [55] & modelica model, physical model + data model & cross-domain communication \\
\hline Micouin [56] & $\begin{array}{c}\text { made up of a Specification model and } \\
\text { behavioral Design model, can be composite of } \\
\text { multiple spec and design model pairs }\end{array}$ & validation through simulation \\
\hline Song et al. [57] & $\begin{array}{c}\text { model that provides key performance } \\
\text { parameters of the system starting at the } \\
\text { beginning of the design }\end{array}$ & derive simulation \\
\hline
\end{tabular}


Table A6. Cont.

\begin{tabular}{|c|c|c|}
\hline Reference & Definition & Purpose \\
\hline Pfluegl et al. [58] & series of interconnected domain models & monitoring \\
\hline Acker et al. [59] & $\begin{array}{l}\text { composed of models of the subsystems, } \\
\text { in general one level of abstraction, sometimes } \\
\text { more levels of abstraction combined; } \\
\text { computation, communication and control } \\
\text { models }\end{array}$ & system simulation, transfer to simulink \\
\hline Aboutaleb and Monsuez [60] & $\begin{array}{l}\text { shows system complexity, set of components, } \\
\text { interrelations and their intensity }\end{array}$ & early system design/architecture \\
\hline $\begin{array}{l}\text { Morkevicius and Jankevicius } \\
\text { [61] }\end{array}$ & SysML & Requirements verification \\
\hline Tschirner et al. [62] & graphical model of the system (SysML/OPM) & $\begin{array}{c}\text { core of MBSE, enabling consistent } \\
\text { specification of product from different } \\
\text { viewpoints, requirements, structure, behavior, } \\
\text { concepts /e.g., sketches), makes dependencies } \\
\text { visible, one system model, data basis for all } \\
\text { disciplines }\end{array}$ \\
\hline Kaslow [63] & $\begin{array}{l}\text { single source of truth, integrates other models } \\
\text { and simulations }\end{array}$ & integrates other models \\
\hline Kaslow et al. [64] & integration of domain specific models & integrates other models \\
\hline Holtmann et al. [65] & SysML & $\begin{array}{c}\text { coordinate disciplines }(\mathrm{E} / \mathrm{E}, \mathrm{Mech}, \mathrm{SW}) \text {, } \\
\text { common understanding , starting point fir } \\
\text { domain specific engineering, generate } \\
\text { software spec }\end{array}$ \\
\hline Dumitrescu et al. [66] & graphic models, SysML & derive behavioral models \\
\hline Iwata et al. [67] & $\begin{array}{l}\text { single model in SysML or similar (can consist } \\
\text { of multiple SysML diagrams) that integrates } \\
\text { other design and modeling information }\end{array}$ & $\begin{array}{l}\text { visualize the concurrent activities and identify } \\
\text { conflicts more efficiently }\end{array}$ \\
\hline Hampson [68] & system architecture + system parameters & $\begin{array}{l}\text { perform verification of its value properties } \\
\text { post-analysis against the requirements }\end{array}$ \\
\hline Aboutaleb and Monsuez [69] & $\begin{array}{l}\text { holistic integration of models that provide a } \\
\text { single source of truth across domains }\end{array}$ & $\begin{array}{l}\text { collaborate across domains, manage } \\
\text { complexity beyond "divide and conquer" }\end{array}$ \\
\hline Cheng and Zhou [70] & common information model & active monitoring \\
\hline Johnson et al. [71] & $\begin{array}{l}\text { physic based models of robot system, model } \\
\text { of hybrid dynamic system, number of } \\
\text { assumptions for mathematical model }\end{array}$ & analysis \\
\hline Kulkarni et al. [72] & SysML model & evaluate design decisions \\
\hline Sindiy et al. [73] & SysML & $\begin{array}{l}\text { multi-user accessible, reporting (web-based } \\
\text { extracted), single source of truth (main source } \\
\text { of project information), needs to be center of } \\
\text { MBSE infrastructure, partial write access } \\
\text { through view editor, stored in system model } \\
\text { repository }\end{array}$ \\
\hline Brecher et al. [74] & $\begin{array}{l}\text { IML, self developed, based on UML, SysML, } \\
\text { FAD, Consens }\end{array}$ & $\begin{array}{c}\text { communication, extract discipline specific } \\
\text { information }\end{array}$ \\
\hline Vannesjo et al. [75] & DEQ & support development \\
\hline Henke et al. [76] & $\begin{array}{l}\text { requirements and architecture, connected with } \\
\text { domain models via SysML }\end{array}$ & tracing \\
\hline Pleshkova and Zahariev [77] & graphical model of the system (SysML/OPM) & design of systems \\
\hline Wu et al. [78] & $\begin{array}{l}\text { behavior and block model of the hybrid } \\
\text { AC/DC system }\end{array}$ & reflect electromagnetic properties \\
\hline
\end{tabular}


Table A6. Cont.

\begin{tabular}{|c|c|c|}
\hline Reference & Definition & Purpose \\
\hline Qu et al. [79] & behavior model, multi-agent system & simulate emergence \\
\hline Kaslow et al. [80] & commonly uses SysML & Single source of truth \\
\hline Watson et al. [81] & $\begin{array}{l}\text { SysML-series of tightly integrated and } \\
\text { interrelated models that form a complete } \\
\text { system model }\end{array}$ & $\begin{array}{l}\text { integrate human interaction into system } \\
\text { development }\end{array}$ \\
\hline Fischer et al. [82] & $\begin{array}{l}\text { database, for the whole lifecylce, several for } \\
\text { different phases, central source of truth for } \\
\text { system relevant information }\end{array}$ & $\begin{array}{l}\text { organize information for everyone and keep } \\
\text { data consistent }\end{array}$ \\
\hline Rambikur et al. [83] & $\begin{array}{l}\text { word not used in text, but speaks of system } \\
\text { modeling (behavior and architecture models) }\end{array}$ & fault tree anaylsis \\
\hline Friedl et al. [84] & descriptive SysML model & $\begin{array}{l}\text { NOT the main focus of SysML to run } \\
\text { simulation, should supprt calculations, } \\
\text { automatical generate executable (Simulink) } \\
\text { models out of (SysML system model) }\end{array}$ \\
\hline Kößler and Paetzold [85] & $\begin{array}{c}\text { complementing domain specific models, core } \\
\text { of SysML }\end{array}$ & $\begin{array}{l}\text { enable consistency of data, visualization, } \\
\text { understanding of complete system, } \\
\text { communication, calculate the fulfillment of } \\
\text { requirement with less effort, representf } \\
\text { dependencies between different domain's } \\
\text { data }\end{array}$ \\
\hline Hanson et al. [86] & SysML model & improve integration and collaboration \\
\hline Parrott and Weiland [87] & SysML model & technical reviews \\
\hline Anyanhun and Edmonson [88] & concept model (SysML) & requirements definition \\
\hline Wang et al. [89] & SysML model & document change propagation \\
\hline
\end{tabular}

meta-model, similar to database, merged

Fischer et al. [90] knowledge of engineer, stores current design of system

Kübler et al. [91]

Madni and Sievers [2]

Bossa et al. [92] capella model

living representation' of a system that continues to evolve as details are incrementally added throughout the system's lifecycle focus on common tasks, feedback to engineers, hierarchical decomposition of system, on-the-fly analysis

single source of truth, lifecylce management, collaboration, provide view points

single source of truth, $\mathrm{V} \& \mathrm{~V}$

\begin{tabular}{|c|c|c|}
\hline Bossa et al. [92] & capella model & $\begin{array}{l}\text { starting point for the definition of a } \\
\text { co.simulation platform model }\end{array}$ \\
\hline Papakonstantinou et al. [93] & $\begin{array}{l}\text { multidisciplinary model of the system under } \\
\text { development }\end{array}$ & $\begin{array}{l}\text { used for safety and security assessment as } \\
\text { well as communicating information between } \\
\text { all system stakeholders }\end{array}$ \\
\hline Gaskell and Harrison [94] & $\begin{array}{l}\text { more connected and dynamic definition of a } \\
\text { system, DSM, (SysML/OPM model) }\end{array}$ & SETR with metrics in meta-model \\
\hline Wang et al. [95] & connected SysML diagrams & creation of highly integrated product model \\
\hline $\begin{array}{c}\text { Duncan and Etienne-Cummings } \\
\text { [96] }\end{array}$ & SysML (can be integrated with Matlab) & $\begin{array}{l}\text { trade-off and analytics using FEA, Single } \\
\text { source of truth }\end{array}$ \\
\hline Kunnen et al. [97] & $\begin{array}{l}\text { continuous data model with usage of } \\
\text { modeling language, here SysML }\end{array}$ & $\begin{array}{l}\text { identification of errors and risk = identify } \\
\text { negative influences and risk }\end{array}$ \\
\hline Buldakova [98] & ONLY behavioral black box model & $\begin{array}{l}\text { study real processes or phenomena and the } \\
\text { control system as well as the system response; } \\
\text { classification of system states, forecast of } \\
\text { changes, assessment of system description } \\
\text { completeness and parameter sufficiency }\end{array}$ \\
\hline
\end{tabular}


Table A6. Cont.

\begin{tabular}{|c|c|c|}
\hline Reference & Definition & Purpose \\
\hline Stevens [99] & $\begin{array}{c}\text { connection of various models which are } \\
\text { accepted and maintained as authorative } \\
\text { representation }\end{array}$ & $\begin{array}{l}\text { development of concepts, understanding of } \\
\text { real system and inform decision makers, } \\
\text { improve communication }\end{array}$ \\
\hline Konrad et al. [100] & $\begin{array}{l}\text { graphical modeling language model (here } \\
\text { SysML) }\end{array}$ & $\begin{array}{l}\text { support the development process, } \\
\text { visualization of processes, identification of } \\
\text { complexity drivers, complexity management }\end{array}$ \\
\hline Baklouti et al. [101] & $\begin{array}{l}\text { SysML with included system requirements, } \\
\text { behavior, architecture and functions }\end{array}$ & generation of FMEA and fault tree \\
\hline Bagdatli et al. [102] & SysML & $\begin{array}{l}\text { single source of truth, design space } \\
\text { exploration }\end{array}$ \\
\hline Gao et al. [103] & $\begin{array}{l}\text { SysML based digital system model or sets of } \\
\text { models that help integrate other discipline } \\
\text { specific engineering models and simulations, } \\
\text { which is initiated at the start and evolves } \\
\text { through the system's lifecycle }\end{array}$ & $\begin{array}{l}\text { used or integration and to support } \\
\text { optimization, simulation and analysis }\end{array}$ \\
\hline Kamburjan and Stromberg [104] & $\begin{array}{l}\text { formal model of a real target system that } \\
\text { mirrors structure and behavior sufficiently for } \\
\text { prototyping and to evaluate changes, digital } \\
\text { twins are a variant of this }\end{array}$ & $\begin{array}{l}\text { prototyping and to evaluate changes and } \\
\text { digital twins }\end{array}$ \\
\hline Duhil et al. [105] & system architecture & Simulation (when enriched) \\
\hline Zimmermann et al. [106] & $\begin{array}{l}\text { model that integrates requirements and } \\
\text { architecture }\end{array}$ & $\begin{array}{c}\text { generating dynamic models and viewpoints, } \\
\text { supporting digital twin application }\end{array}$ \\
\hline Mei et al. [107] & $\begin{array}{l}\text { integrated multi-domain model incl. a } \\
\text { "transformer model" for integrating all } \\
\text { comprising models, created through bottom } \\
\text { up integration of component and subsystem } \\
\text { models }\end{array}$ & simulation, prediction and system $\mathrm{V} \& \mathrm{~V}$ \\
\hline
\end{tabular}

\section{Appendix B. Arxiv Export Code}

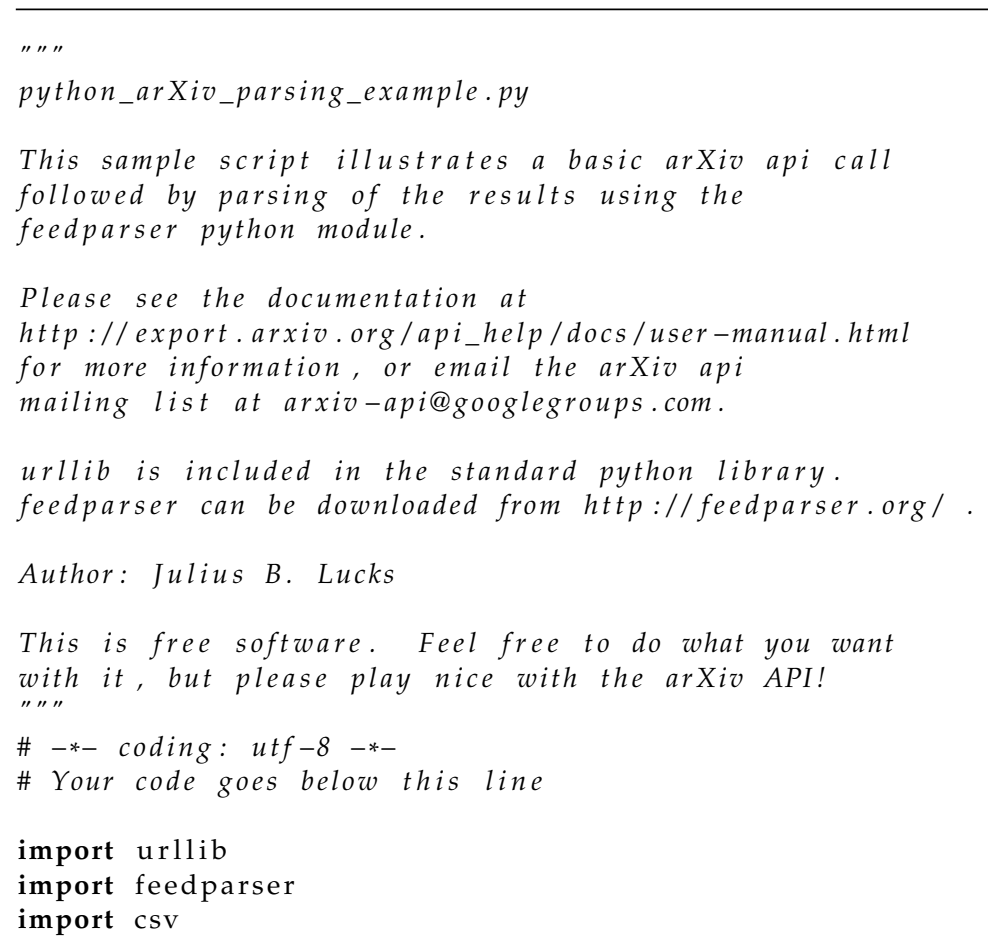


\# Base api query url

base_url = 'http://export.arxiv.org/api/query?' ;

\# Search parameters

search_query = ' a $11:$ mbse+OR+a $11:$ system+AND+a $11:$ model+AND+Engineering '

\# search for electron in all fields

start $=0$

\# retrieve the first $x$ results

max_results = 1000

query = 'search_query=\%s\&start=\%i\&max_results=\%i' \% ( search_query,

start,

max_results )

\# Opensearch metadata such as totalResults, startIndex,

\# and itemsPerpage live in the opensearch namespase.

\# Some entry metadata lives in the arXiv namespace.

\# This is a hack to expose both of these namespaces in

\# feedparser v4.1

feedparser._FeedParserMixin . namespaces [

'http://a9.com/-/spec/opensearch/1.1/'] = 'opensearch'

feedparser._FeedParserMixin . namespaces [

'http://arxiv.org/schemas/atom'] = 'arxiv'

\# perform a GET request using the base_url and query

response $=$ urllib.urlopen $($ base_url+query $) \cdot \operatorname{read}()$

\# parse the response using feedparser

feed $=$ feedparser $\cdot$ parse $($ response $)$

\# print out feed information

print 'Feed title: \%s' \% feed.feed.title

print 'Feed ${ }_{\sqcup}$ last $t_{\sqcup}$ updated: $\%$ s' \% feed.feed.updated

\# print opensearch metadata

print 'totalResults for this query: $\%{ }$ ' $\%$ feed.feed.opensearch_totalresults

print 'itemsPerPage for this $e_{\sqcup}$ query: $\%$ s' \% feed.feed.opensearch_itemsperpage

print 'startIndex for $_{\sqcup}$ this $s_{\sqcup} q u e r y:_{\sqcup} \% s^{\prime} \%$ feed.feed.opensearch_startindex

\# Run through each entry, and print out information count $=0$

with open('arxiv_query_result.csv', 'wb') as csvfile:

filewriter $=$ csv. writer (csvfile, delimiter $=^{\prime}$; ', quotechar $={ }^{\prime} \mid{ }^{\prime}$, quoting $=$ csv.QUOTE_MINIMAL)

filewriter. writerow ([

"ID",

"Published"

"Title",

"Link",

"A11_Authors",

"Abstract",

"Primary_Category" ])

for entry in feed.entries:

print "RECORD NO: "

print count

print 'e-print metadata'

print 'arxiv-id: \%s' \% entry.id.split ('/abs/')[-1]

print 'Published: $\%$ s' $\%$ entry.published

print 'Title: $\%$ os' \% entry.title

\# feedparser v4.1 only grabs the first author

author_string = entry.author

\# grab the affiliation in <arxiv:affiliation> if present

\# - this will only grab the first affiliation encountered 
\# (the first affiliation for the first author)

\# Please email the list with a way to get all of this information!

try :

author_string $+={ }^{\prime}(\%$ s $){ }^{\prime} \%$ entry.arxiv_affiliation

except AttributeError:

pass

print 'Last_Author: ${ }_{\sqcup} \% \mathrm{~s}^{\prime} \%$ author_string

\# feedparser v5.0.1 correctly handles multiple authors, print them all try :

print 'Authors: $\% s^{\prime} \%$ ', ', join (author.name for author in entry. authors )

all_authors $={ }^{\circ} \% \mathrm{~s}^{\prime} \%{ }^{\prime}, \mathrm{c}^{\prime}$.join (author. name for author in entry. authors )

all_authors = all_authors.encode $($ errors $="$ replace" $)$

print all_authors

except AttributeError:

pass

\# get the links to the abs page and pdf for this e-print

for link in entry.links:

if link. rel == 'alternate':

print 'abs page link: \%s' \% link.href

elif link. title == 'pdf':

print 'pdf link: \%s' \% link.href

\# The journal reference, comments and primary_category sections live under

\# the arxiv namespace

try:

journal_ref $=$ entry.arxiv_journal_ref

except AttributeError:

journal_ref $=$ 'No journal ref $_{\sqcup}$ found'

print 'Journal_reference: \%s' \% journal_ref

try :

comment $=$ entry $\cdot$ arxiv_comment

except AttributeError:

comment $={ }^{\prime} \mathrm{No}_{\sqcup}$ comment found $^{\prime}$

print 'Comments: \%s' \% comment

\# Since the <arxiv:primary_category> element has no data, only

\# attributes, feedparser does not store anything inside

\# entry.arxiv_primary_category

\# This is a dirty hack to get the primary_category, just take the

\# first element in entry.tags. If anyone knows a better way to do

\# this, please email the list!

\#so far only last author!

print 'Primary ${ }_{\sqcup}$ Category: $\%$ s' \% entry.tags [0][ 'term']

\# Lets get all the categories

all_categories $=[\mathrm{t}[$ 'term'] for $\mathrm{t}$ in entry.tags $]$

print 'All_Categories: ${ }_{\smile} \% \mathrm{~s}^{\prime} \%\left({ }^{\prime},{ }^{\prime}{ }^{\prime}\right)$. join (all_categories)

\# The abstract is in the <summary> element

print 'Abstract: $\%$ s' \% entry .summary

primary_cat $=$ comment, entry.tags [0]['term']

primary_cat $=$ primary_cat.replace $(" ; ", ", ")$

entryid = entry.id

enrtyid = entryid.encode $($ errors $=$ "replace" $)$

entrypub= entry $\cdot$ published

entrypub $=$ entrypub. encode $($ errors $=$ "replace" $)$

entrypub = entrypub. replace $(" \backslash r ", "$ ")

entrypub $=$ entrypub. replace $(" \backslash n ", "$ ") 


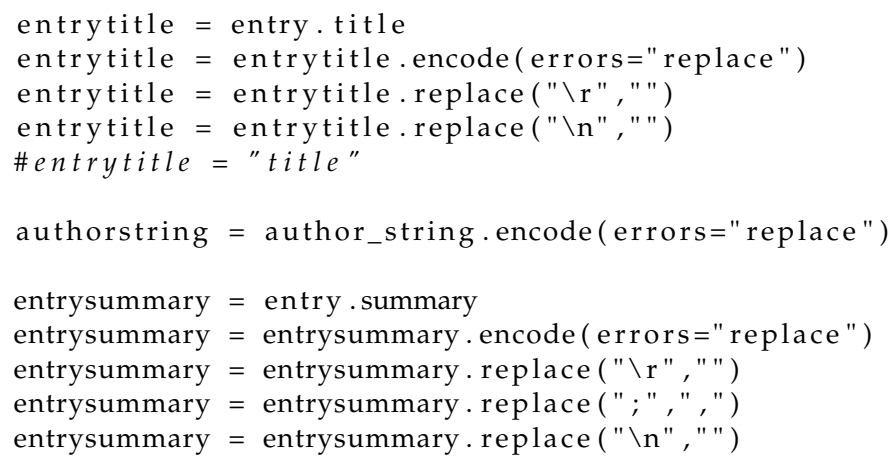

\section{References}

1. Huldt, T.; Stenius, I. State-of-practice survey of model-based systems engineering. Syst. Eng. 2018, 22, 134-145. [CrossRef]

2. Madni, A.M.; Sievers, M. Model-based systems engineering: Motivation, current status, and research opportunities. Syst. Eng. 2018, 21, 172-190. [CrossRef]

3. Hart, L.E. Introduction To Model-Based System Engineering (MBSE) and SysML. In Proceedings of the Delaware Valley INCOSE Chapter Meeting, Mt. Laurel, NJ, USA, 30 July 2015.

4. Moher, D.; Liberati, A.; Tetzlaff, J.; Altman, D.G. Preferred Reporting Items for Systematic Reviews and Meta-Analyses: The PRISMA Statement. PLoS Med. 2009, 6, e1000097. [CrossRef]

5. Capehart, B.L. Simulation of continuous system models in industrial engineering. Comput. Ind. Eng. 1977, 1, 207-216. [CrossRef]

6. Joshi, S.; Mettala, E.; Smith, J.; Wysk, R. Formal models for control of flexible manufacturing cells: Physical and system model. IEEE Trans. Robot. Autom. 1995, 11, 558-570. [CrossRef]

7. Ironmonger, S.; Bushnell, M.; Patel, R.; Vaughan, W. An object-oriented power system model and graphical information display system for control engineers. In Proceedings of the Fourth International Conference on Power System Control and Management, London, UK, 16-18 April 1996. [CrossRef]

8. Bluff, R. An avionic system modeling framework. In Proceedings of the Modeling and Simulation Technologies Conference and Exhibit. American Institute of Aeronautics and Astronautics, Portland, OR, USA, 9-11 August 1999. [CrossRef]

9. Bluff, R.J. Integrated modular avionics: System modelling. Microprocess. Microsyst. 1999, 23, 435-448. [CrossRef]

10. Estanbouli, Y.; Hayward, G.; Ramadas, S.; Barbenel, J. A linear systems model of the thickness mode piezoelectric transducer containing dual piezoelectric zones. In Proceedings of the IEEE Ultrasonics Symposium, Montreal, QC, Canada, 23-27 August 2004. [CrossRef]

11. Hicks, B.J.; Culley, S.J.; Mullineux, G. The Modeling of Engineering Systems for Their Computer-Based Embodiment With Standard Components. J. Mech. Des. 2004, 127, 424-432. [CrossRef]

12. Wilson, A.G.; McNamara, L.A.; Wilson, G.D. Information integration for complex systems. Reliab. Eng. Syst. Saf. 2007, 92, 121-130. [CrossRef]

13. Che, J.; Jennings, M. Vehicle System Modeling for HEV Systems Development. In Proceedings of the 27th Computers and Information in Engineering Conference, Las Vegas, NV, USA, 4-7 September 2007. [CrossRef]

14. Ma, J.; Ma, Y.-g.; Wang, B.-s. Dynamic characteristic optimization for superheater system model based on evolutionary computation. In Proceedings of the 2008 Asia Simulation Conference-7th International Conference on System Simulation and Scientific Computing, Beijing, China, 10-12 October 2008. [CrossRef] 
15. Curry, G.L.; Coulson, R.N.; Gan, J.; Tchakerian, M.D.; Smith, C.T. An Optimization-Based System Model of Disturbance-Generated Forest Biomass Utilization. Bull. Sci. Technol. Soc. 2008, 28, 486-495. [CrossRef]

16. Sturm, A. Guiding System Modelers in Multi View Environments: A Domain Engineering Approach. In Proceedings of the EMMSAD 2008, Montpellier, France, 16-17 June 2008.

17. Wakefield, A.; Miller, S. Improving System Models by Using Monte Carlo Techniques on Plant Models. In Proceedings of theAIAA Modeling and Simulation Technologies Conference and Exhibit. American Institute of Aeronautics and Astronautics, Honolulu, HI, USA, 18-21 August 2008. [CrossRef]

18. Amrhein, M.; Wells, J.R.; Walters, E.A.; Matasso, A.F.; Erdman, T.R.; Iden, S.M.; Lamm, P.L.; Page, A.M.; Wong, I.H. Integrated Electrical System Model of a More Electric Aircraft Architecture; SAE Technical Paper Series; SAE International: Warrendale, PA, USA, 2008. [CrossRef]

19. Hoang, H.; Fu, S.J.; Dinh, V. Integrated Electrical System Testing and Modeling for Risk Mitigation; SAE Technical Paper Series; SAE International: Warrendale, Pennsylvania 2008, [CrossRef]

20. Hummel, B.; Braun, P. Towards an integrated system model for testing and verification of automation machines. In Proceedings of the 2008 International Workshop on Models in Software Engineering-MiSE '08, Leipzig, Germany, 10-18 May 2008. [CrossRef]

21. Swerdon, G.; Watson, M.; Bhardwaj, S.; Byington, C.; Smith, M.; Goebel, K.; Balaban, E. A Systems Engineering Approach to Electro-Mechanical Actuator Diagnostic and Prognostic Development. Available online: https://www.academia.edu/23586707 /A_Systems_Engineering_Approach_to_Electro_Mechanical_Actuator_Diagnostic_and_Prognostic_Development (accessed on 11 October 2020).

22. Qamar, A.; During, C.; Wikander, J. Designing mechatronic systems, a model-based perspective, an attempt to achieve SysMLMatlab/Simulink model integration. In Proceedings of the 2009 IEEE/ASME International Conference on Advanced Intelligent Mechatronics, Singapore, 14-17 July 2009. [CrossRef]

23. Li, X.; Xiong, H. Modeling and analysis of integrated avionics processing systems. In Proceedings of the 29th Digital Avionics Systems Conference, Salt Lake City, UT, USA, 3-7 October 2010. [CrossRef]

24. Dickerson, C.; Valerdi, R. Using relational model transformations to reduce complexity in SoS requirements traceability: Preliminary investigation. In Proceedings of the 2010 5th International Conference on System of Systems Engineering, Loughborough, UK, 22-24 June 2010. [CrossRef]

25. Borutzky, W. Bond Graph Methodology; Springer: London, UK, 2010. [CrossRef]

26. Follmer, M.; Hehenberger, P.; Punz, S.; Zeman, K. Using SysML in the product development process of mechatronic systems. In Proceedings of the 11th International Design Conference, DESIGN 2010, Dubrovnik, Croatia, 17-20 May 2010; pp. 1513-1522.

27. Stetter, R.; Seemüller, H.; Chami, M.; Voos, H. Interdisciplinary System Model for Agent-Supported Mechatronic Design. In Proceedings of the International Conference on Engineering Design, ICED11, Copenhagen, Denmark, $15-18$ August 2011.

28. Kleins, A.; Teilans, A.; Merkuryev, Y.; Krasts, O. A Metamodel Based Approach for UML Notated Domain Specific Modelling Language. In Proceedings of the 2011 UkSim 13th International Conference on Computer Modelling and Simulation, Cambridge, UK, 30 March-1 April 2011. [CrossRef]

29. Witsch, M.; Vogel-Heuser, B. Formal MES Modeling Framework -Integration of Different Views. IFAC Proc. Vol. 2011, 44, 14109-14114. [CrossRef]

30. Schütz, D.; Vogel-Heuser, B. Modellintegration von Verhaltens- und energetischen Aspekten für mechatronische Module. Automatisierungstechnik 2011, 59. [CrossRef]

31. Piaszczyk, C. Model Based Systems Engineering with Department of Defense Architectural Framework. Syst. Eng. 2011, 14, 305-326. [CrossRef]

32. Guan, H.; Hao, W.T.; Zhan, J. A Characteristic Brake System Model for Passenger Car. Appl. Mech. Mater. 2012, 224, 316-319. [CrossRef]

33. Strahilov, A.; Ovtcharova, H.C.J.; Bar, T. Development of the physics-based assembly system model for the mechatronic validation of automated assembly systems. In Proceedings of the 2012 Winter Simulation Conference (WSC), Berlin, Germany, 9-12 December 2012. [CrossRef]

34. Magalhães, P.; Martins, J.; Joyce, A.; Coelho, L.; Tavares, N.; Pereira, R. Solar Trigeneration System Model for Off-Grid Residential Applications. In Technological Innovation for Value Creation; Camarinha-Matos, L., Ed.; Springer: Berlin/Heidelberg, Germany, 2012; Volume 372, pp. 375-384. [CrossRef]

35. Hoffmann, H. Streamlining the development of complex systems through model-based systems engineering. In Proceedings of the 2012 IEEE/AIAA 31st Digital Avionics Systems Conference (DASC), Williamsburg, VA, USA, 14-18 October 2012. [CrossRef]

36. Ahn, H.J.; Shim, K.S.; Lim, Y.C.; Ko, Y.J.; Park, K.M.; Baek, I.H.; Ro, Y.S.; Kim, E.S. System modeling and controller design using time series data. In Proceedings of the 2012 12th International Conference on Control, Automation and Systems, Jeju, Korea, 17-21 October 2012.

37. Chandraiah, P.; Dömer, R. Computer-Aided Recoding to Create Structured and Analyzable System Models. ACM Trans. Embed. Comput. Syst. 2012, 11S, 1-27. [CrossRef]

38. Kim, H.; Fried, D.; Menegay, P.; Soremekun, G. Integrated Modeling and Analysis to Support Model-Based Systems Engineering. In Proceedings of the ASME 2012 11th Biennial Conference on Engineering Systems Design and Analysis, Nantes, France, 2-4 July 2012. [CrossRef] 
39. Schmelcher, J.; Stetter, R.; Kaufmann, A.; Voos, H. Interdisciplinary System Model For Agent Based Mechatronic Design of Turbocharing Systems. In Proceedings of theInternational Design Conference-Design 2012, Dubrovnik, Croatia, 21-24 May 2012.

40. Reichwein, A.; Paredis, C.J.J.; Canedo, A.; Witschel, P.; Stelzig, P.E.; Votintseva, A.; Wasgint, R. Maintaining consistency between system architecture and dynamic system models with SysML4Modelica. In Proceedings of the 6th International Workshop on Multi-Paradigm Modeling-MPM '12, Innsbruck, Austria, 1-5 October 2012. [CrossRef]

41. Follmer, M.; Hehenberger, P.; Zeman, K. Model-Based Approach for the Reliability Prediction of Mechatronic Systems on the System-Level. In Computer Aided Systems Theory_EUROCAST 2011; Springer: Berlin/Heidelberg, Germany, $2012 ;$ pp. 105-112. [CrossRef]

42. Ramos, A.L.; Ferreira, J.V.; Barcelo, J. Model-Based Systems Engineering: An Emerging Approach for Modern Systems. IEEE Trans. Syst. Man Cybern. Part C 2012, 42, 101-111. [CrossRef]

43. Becherini, F.; Cencetti, M.; Pasquinelli, M. System Model Optimization through Functional Models Execution: Methodology and Application to System-Level Analysis. In Proceedings of the 2012 IEEE 21st International Workshop on Enabling Technologies: Infrastructure for Collaborative Enterprises, Toulouse, France, 25-27 June 2012. [CrossRef]

44. Glas, M.; Sartorius, S. Towards a continuous build-up process of a reusable requirements-based system model. In Proceedings of the 2012 IEEE Aerospace Conference, Big Sky, MT, USA, 3-10 March 2012. [CrossRef]

45. Wang, A.L.; Wang, Q.J. An Improved Model Reduction Method and its Application in Similar Simulation of Complex Systems. Adv. Mater. Res. 2013, 744, 8-12. [CrossRef]

46. Ma, Y.L.; Chen, X.H.; Liu, B.; Zhang, G.F. Energy Efficiency Assessment Oriented Building Energy Consumption System Model. Appl. Mech. Mater. 2013, 415, 734-740. [CrossRef]

47. Zander, J. Model-based testing for execution algorithms in the simulation of cyber-physical systems. In Proceedings of the 2013 IEEE Autotestcon, Schaumburg, IL, USA, 16-19 September 2013. [CrossRef]

48. Haveman, S.P.; Bonnema, G.M. Requirements for High Level Models Supporting Design Space Exploration in Model-based Systems Engineering. Procedia Comput. Sci. 2013, 16, 293-302. [CrossRef]

49. Nattermann, R.; Anderl, R. The W-Model-Using Systems Engineering for Adaptronics. Procedia Comput. Sci. 2013, 16, 937-946. [CrossRef]

50. Sharon, A.; de Weck, O.L.; Dori, D. Improving Project-Product Lifecycle Management with Model-Based Design Structure Matrix: A joint project management and systems engineering approach. Syst. Eng. 2013, 16, 413-426. [CrossRef]

51. Gausemeier, J.; Gaukstern, T.; Tschirner, C. Systems Engineering Management Based on a Discipline-Spanning System Model. Procedia Comput. Sci. 2013, 16, 303-312. [CrossRef]

52. Broy, M. A Model of Dynamic Systems. In From Programs to Systems. The Systems perspective in Computing; Springer: Berlin/Heidelberg, Germany, 2014; pp. 39-53. [CrossRef]

53. Barbieri, G.; Kernschmidt, K.; Fantuzzi, C.; Vogel-Heuser, B. A SysML based design pattern for the high-level development of mechatronic systems to enhance re-usability. IFAC Proc. Vol. 2014, 47, 3431-3437. [CrossRef]

54. Zierolf, M.L.; Brinson, T.; Fleming, A. Integrated System Modeling; SAE Technical Paper Series; SAE International: Warrendale, PA, USA, 2014. [CrossRef]

55. Komoto, H.; Kondoh, S.; Masui, K.; Tezuka, A. Parameter-oriented Visualization of a Modelica Model with a Numerical Data Integration Feature. Procedia CIRP 2014, 21, 40-45. [CrossRef]

56. Micouin, P. Property-Model Methodology: A Model-Based Systems Engineering Approach Using VHDL-AMS. Syst. Eng. 2013, 17, 249-263. [CrossRef]

57. Song, Y.; Cao, K.; Zhang, D. The research on system-level modeling technology of mixed-level abstraction. In Proceedings of the 2014 International Conference on Anti-Counterfeiting, Security and Identification (ASID), Macao, China, 12-14 December 2014. [CrossRef]

58. Pfluegl, H.; Ricci, C.; Borgarello, L.; Magnin, P.; Sellier, F.; Berzi, L.; Pierini, M.; Mazal, C.; Benzaoui, H. A Framework for Electric Vehicle Development: From Modelling to Engineering Through Real-World Data Analysis. In Electric Vehicle Systems Architecture and Standardization Needs; Springer: Berlin/Heidelberg, Germany, 2015; pp. 55-73. [CrossRef]

59. Acker, B.V.; Denil, J.; Vangheluwe, H.; Meulenaere, P.D. Managing Heterogeneity in Model-Based Systems Engineering of Cyber-Physical Systems. In Proceedings of the 2015 10th International Conference on P2P, Parallel, Grid, Cloud and Internet Computing (3PGCIC), Krakow, Poland, 4-6 November 2015. [CrossRef]

60. Aboutaleb, H.; Monsuez, B. Measuring the Complexity of a Higraph-based System Model: Formalism and Metrics. Procedia Comput. Sci. 2015, 44, 11-20. [CrossRef]

61. Morkevicius, A.; Jankevicius, N. An approach: SysML-based automated requirements verification. In Proceedings of the 2015 IEEE International Symposium on Systems Engineering (ISSE), Rome, Italy, 28-30 September 2015. [CrossRef]

62. Tschirner, C.; Bretz, L.; Dumitrescu, R.; Gausemeier, J. Applying Model-Based Systems Engineering for Product Engineering Management concepts for industrial application. In Proceedings of the 2015 IEEE International Symposium on Systems Engineering (ISSE), Rome, Italy, 28-30 September 2015. [CrossRef]

63. Kaslow, D. CubeSat Model Based System Engineering (MBSE) Reference Model - Application in the Concept Lifecycle Phase. In Proceedings of the AIAA SPACE 2015 Conference and Exposition, Pasadena, CA, USA, 31 August-2 September 2015. [CrossRef] 
64. Kaslow, D.; Anderson, L.; Asundi, S.; Ayres, B.; Iwata, C.; Shiotani, B.; Thompson, R. Developing a CubeSat Model-Based System Engineering (MBSE) Reference Model-Interim status. In Proceedings of the 2015 IEEE Aerospace Conference, Big Sky, MT, USA, 7-14 March 2015. [CrossRef]

65. Holtmann, J.; Bernijazov, R.; Meyer, M.; Schmelter, D.; Tschirner, C. Integrated systems engineering and software requirements engineering for technical systems. In Proceedings of the 2015 International Conference on Software and System Process-ICSSP 2015, Tallinn, Estonia, 24-26 August 2015. [CrossRef]

66. Dumitrescu, R.; Bremer, C.; Kühn, A.; Trächtler, A.; Frieben, T. Model-based development of products, processes and production resources. Automatisierungstechnik 2015, 63. [CrossRef]

67. Iwata, C.; Infeld, S.; Bracken, J.M.; McGuire, M.; McQuirck, C.; Kisdi, A.; Murphy, J.; Cole, B.; Zarifian, P. Model-Based Systems Engineering in Concurrent Engineering Centers. In Proceedings of the AIAA SPACE 2015 Conference and Exposition, Pasadena, CA, USA, 31 August-2 September 2015. [CrossRef]

68. Hampson, K. Technical Evaluation of the Systems Modeling Language (SysML). Procedia Comput. Sci. 2015, 44, 403-412. [CrossRef]

69. Aboutaleb, H.; Monsuez, B. Towards a Holistic Definition of System Engineering: Paradigm and Modeling Requirements. In Progress in Systems Engineering; Springer: Berlin/Heidelberg, Germany, 2015; pp. 603-608. [CrossRef]

70. Cheng, Y.; Zhou, Y. A CIM extended power transmission and transformation on-line monitoring system model. In Proceedings of the 2016 7th IEEE International Conference on Software Engineering and Service Science (ICSESS), Beijing, China, 26-28 August 2016. [CrossRef]

71. Johnson, A.M.; Burden, S.A.; Koditschek, D.E. A hybrid systems model for simple manipulation and self-manipulation systems. Int. J. Robot. Res. 2016, 35, 1354-1392. [CrossRef]

72. Kulkarni, T.; DeBruin, K.; Nelessen, A.; Reilley, K.A.; Peak, R.; Edwards, S.J.; Mavris, D.N. A Model Based Systems Engineering Approach Towards Developing a Rapid Analysis and Trades Environment. In Proceedings of the AIAA SPACE 2016, Long Beach, CA, USA, 13-16 September 2016. [CrossRef]

73. Sindiy, O.; Mozafari, T.; Budney, C. Application of Model-Based Systems Engineering for the Development of the Asteroid Redirect Robotic Mission. In Proceedings of the AIAA SPACE 2016, Long Beach, CA, USA, 13-16 September 2016. [CrossRef]

74. Brecher, C.; Obdenbusch, M.; Ozdemir, D.; Flender, J.; Weber, A.R.; Jordan, L.; Witte, M. Interdisciplinary specification of functional structures for machine design. In Proceedings of the 2016 IEEE International Symposium on Systems Engineering (ISSE), Edinburgh, UK, 3-5 October 2016. [CrossRef]

75. Vannesjo, S.J.; Duerst, Y.; Vionnet, L.; Dietrich, B.E.; Pavan, M.; Gross, S.; Barmet, C.; Pruessmann, K.P. Gradient and shim pre-emphasis by inversion of a linear time-invariant system model. Magn. Reson. Med. 2016, 78, 1607-1622. [CrossRef]

76. Henke, C.; Michael, J.; Lankeit, C.; Trachtler, A. A holistic approach for virtual commissioning of intelligent systems: Model-based systems engineering for the development of a turn-milling center. In Proceedings of the 2017 Annual IEEE International Systems Conference (SysCon), Montreal, QC, Canada, 24-27 April 2017. [CrossRef]

77. Pleshkova, S.; Zahariev, Z. Development of system model for audio visual control of mobile robots with voice and gesture commands. In Proceedings of the 2017 40th International Spring Seminar on Electronics Technology, Sofia, Bulgaria, 10-14 May 2017. [CrossRef]

78. Wu, Q.; Gouyon, D.; Levrat, É.; Boudau, S. A Review of Know-How Reuse with Patterns in Model-Based Systems Engineering. In Complex Systems Design \& Management; Springer: Berlin/Heidelberg, Germany, 2018; pp. 219-229. [CrossRef]

79. Qu, Q.; He, X.; Cheng, H.; Zhang, W. The Design of SoS Multi-Agent System Model Based on Emergence Imitation. In Proceedings of the 2017 International Conference on Applied Mathematics, Modeling and Simulation (AMMS 2017), Shanghai, China, 26-27 November 2017. [CrossRef]

80. Kaslow, D.; Ayres, B.; Cahill, P.T.; Hart, L.; Yntema, R. A Model-Based Systems Engineering (MBSE) approach for defining the behaviors of CubeSats. In Proceedings of the 2017 IEEE Aerospace Conference, Big Sky, MT, USA, 4-11 March 2017. [CrossRef]

81. Watson, M.E.; Rusnock, C.F.; Colombi, J.M.; Miller, M.E. Human-Centered Design Using System Modeling Language. J. Cogn. Eng. Decis. Mak. 2017, 11, 252-269. [CrossRef]

82. Fischer, P.M.; Lüdtke, D.; Lange, C.; Roshani, F.C.; Dannemann, F.; Gerndt, A. Implementing model-based system engineering for the whole lifecycle of a spacecraft. CEAS Space J. 2017, 9, 351-365. [CrossRef]

83. Rambikur, S.A.; Giammarco, K.; O’Halloran, B. Increasing System Failure Analysis Effectiveness Through Architecture Modeling. Procedia Comput. Sci. 2017, 114, 4-13. [CrossRef]

84. Friedl, M.; Kellner, A.; Weingartner, L. Integration of domain-specific simulation models into descriptive system models by using SysML. In Proceedings of the 2017 IEEE International Systems Engineering Symposium (ISSE), Vienna, Austria, 11-13 October 2017. [CrossRef]

85. Kößler, J.; Paetzold, K. Integration Of Mbse Into Existing Development. In Proceedings of the 21st International Conference on Engineering Design, ICED17, Vancouver, BC, Canada, 21-25 August 2017.

86. Hanson, A.; Mindock, J.; McGuire, K.; Reilly, J.; Cerro, J.; Othon, W.; Rubin, D.; Urbina, M.; Canga, M. Using A Model-Based Systems Engineering Approach For Exploration Medical System Development; International Astronautical Congress (IAC): Adelaide, Australia, 2017. 
87. Parrott, E.; Weiland, K. Using Model-Based Systems Engineering to Provide Artifacts for NASA Project Life-cycle and Technical Reviews. In Proceedings of the AIAA SPACE and Astronautics Forum and Exposition, Orlando, FL, USA, 12-14 September 2017. [CrossRef]

88. Anyanhun, A.I.; Edmonson, W.W. An MBSE conceptual design phase model for inter-satellite communication. In Proceedings of the 2018 Annual IEEE International Systems Conference (SysCon), Vancouver, BC, Canada, 23-26 April 2018. [CrossRef]

89. Wang, H.; Thomson, V.; Tang, C. Change propagation analysis for system modeling using Semantic Web technology. Adv. Eng. Inform. 2018, 35, 17-29. [CrossRef]

90. Fischer, P.M.; Deshmukh, M.; Maiwald, V.; Quantius, D.; Gomez, A.M.; Gerndt, A. Conceptual data model: A foundation for successful concurrent engineering. Concurr. Eng. 2017, 26, 55-76. [CrossRef]

91. Kübler, K.; Scheifele, S.; Scheifele, C.; Riedel, O. Model-Based Systems Engineering for Machine Tools and Production Systems (Model-Based Production Engineering). Procedia Manuf. 2018, 24, 216-221. [CrossRef]

92. Bossa, B.; Boulbene, B.; Dubé, S.; Pantel, M. Towards a Co-simulation Based Model Assessment Process for System Architecture. In Software Technologies: Applications and Foundations; Springer: Berlin/Heidelberg, Germany, 2018; pp. 58-68. [CrossRef]

93. Papakonstantinou, N.; Linnosmaa, J.; Alanen, J.; Bashir, A.Z.; O’Halloran, B.; Bossuyt, D.L.V. Early Hybrid Safety and Security Risk Assessment Based on Interdisciplinary Dependency Models. In Proceedings of the 2019 Annual Reliability and Maintainability Symposium (RAMS), Orlando, FL, USA, 28-31 January 2019. [CrossRef]

94. Gaskell, J.D.; Harrison, C.N. Improved System Engineering Technical Review's Entrance/Exit Criteria with Model Maturity Metrics. In Proceedings of the 2019 International Symposium on Systems Engineering (ISSE), Edinburgh, UK, 1-3 October 2019. [CrossRef]

95. Wang, Y.; Zingel, P.; Anderl, R. A Methodical Approach for Using SysML to Optimize Product Architectures for Industrie 4.0. In Proceedings of the International MultiConference of Engineers and Computer Scientists 2019 IMECS, Hong Kong, China, 13-15 March 2019.

96. Duncan, K.R.; Etienne-Cummings, R. A Model-Based Systems Engineering Approach to Trade Space Exploration of Implanted Wireless Biotelemetry Communication Systems. IEEE Syst. J. 2019, 13, 1669-1677. [CrossRef]

97. Kunnen, S.G.; Adamenko, D.; Pluhnau, R.; Nagarajah, A. An Approach to Integrate Risk Management in Cross-structure SysML-models. Proc. Des. Soc. Int. Conf. Eng. Des. 2019, 1, 3571-3580. [CrossRef]

98. Buldakova, T. Approaches to the Development of Complex Systems Models. In Proceedings of the 2019 XXI International Conference Complex Systems: Control and Modeling Problems (CSCMP), Samara, Russia, 3-6 September 2019. [CrossRef]

99. Stevens, R. Concept Design Using Model Based Systems Engineering. In Proceedings of the 2019 IEEE Aerospace Conference, Big Sky, MT, USA, 2-9 March 2019. [CrossRef]

100. Konrad, C.; Jacobs, G.; Rasor, R.; Riedel, R.; Katzwinkel, T.; Siebrecht, J. Enabling complexity management through merging business process modeling with MBSE. Procedia CIRP 2019, 84, 451-456. [CrossRef]

101. Baklouti, A.; Nguyen, N.; Mhenni, F.; Choley, J.Y.; Mlika, A. Improved Safety Analysis Integration in a Systems Engineering Approach. Appl. Sci. 2019, 9, 1246. [CrossRef]

102. Bagdatli, B.; Karagoz, F.; Reilley, K.A.; Mavris, D.N. MBSE-enabled Interactive Environment for Aircraft Conceptual Sizing \& Synthesis. In Proceedings of the AIAA Scitech 2019 Forum, San Diego, CA, USA, 7-11 January 2019. [CrossRef]

103. Gao, X.; Zhang, Y.; Wang, Z. The Architecture of Digital System Model for Systems-of-Systems Engineering. In Proceedings of the 2019 Chinese Automation Congress (CAC), Hangzhou, China, 22-24 November 2019. [CrossRef]

104. Kamburjan, E.; Stromberg, J. Tool Support for Validation of Formal System Models: Interactive Visualization and Requirements Traceability. Electron. Proc. Theor. Comput. Sci. 2019, 310, 70-85. [CrossRef]

105. Duhil, C.; Babau, J.P.; Lépicier, E.; Voirin, J.L.; Navas, J. Chaining model transformations to develop a system model verification tool. In Proceedings of the 35th Annual ACM Symposium on Applied Computing, Brno, Czech Republic, 30 March 2020. [CrossRef]

106. Zimmermann, T.C.; Masuhr, C.; Stark, R. MBSE-Entwicklungsfähigkeit für Digitale Zwillinge. ZWF Z. FüR Wirtsch. Fabr. 2020, 115, 51-54. [CrossRef]

107. Mei, Z.; Chen, L.; Ding, J. Multi-domain integrated modeling and verification for the ball screw feed system in machine tools. Proc. Inst. Mech. Eng. Part B J. Eng. Manuf. 2020, 234, 1707-1719. [CrossRef] 